\title{
Identification of proteomic and metabolic signatures associated with chemoresistance of human epithelial ovarian cancer
}

\author{
WENJUAN WU ${ }^{1,2}$, QI WANG ${ }^{2}$, FUQIANG YIN ${ }^{2}$, ZHIJUN YANG ${ }^{1}$, WEI ZHANG ${ }^{2}$, HANI GABRA ${ }^{3,4}$ and LI LI ${ }^{1,2}$ \\ ${ }^{1}$ Department of Gynecologic Oncology, Affiliated Tumor Hospital of Guangxi Medical University; \\ ${ }^{2}$ Key Laboratory of High-Incidence Tumor Prevention and Treatment (Guangxi Medical University), Ministry of Education, \\ Nanning, Guangxi 530021, P.R. China; ${ }^{3}$ Section of Molecular Therapeutics, Department of Cancer Medicine, \\ Imperial College London; ${ }^{4}$ West London Gynecological Cancer Centre, London, UK
}

Received May 27, 2016; Accepted July 25, 2016

DOI: 10.3892/ijo.2016.3652

\begin{abstract}
Emerging drug resistance in epithelial ovarian cancer (EOC) thwarted progress in platinum-based chemotherapy, resulting in increased mortality, morbidity and healthcare costs. The aim of this study was to detect the responses induced by chemotherapy at protein and metabolite levels, and to search for new plasma markers that can predict resistance to platinum-based chemotherapy in EOC patients, leading to improved clinical response rates. Serum samples were collected and subjected to proteomic relative quantitation analysis and metabolomic analysis. Differentially expressed proteins and metabolites were subjected to bioinformatics and statistical analysis. Proteins that played a key role in platinum resistance were validated by western blotting and enzyme-linked immunosorbent assay (ELISA). Metabolites that were the main contributors to the groups and closely with clinical characteristics were identified based on the database using nuclear magnetic resonance (NMR). In total, 248 proteins from two independent experiments were identified using isobaric tags for relative and absolute quantitation (iTRAQ)-based quantitative proteomic approach. Among them, FN1, SERPINA1, GPX3 and ORM1 were chosen for western blotting and ELISA validation. Platinum resistance likely associated with differentially expressed proteins and FN1, SERPINA1 and ORM1 may play a positive role in chemotherapy. HPLC-MS analysis of four groups revealed a total of 25,800 metabolic features, of which six compounds were chosen for candidate biomarkers and identified based on the database using NMR. The metabolic signatures of normal control (NC), platinum-sensitive (PTS) and platinum-resistant (PTR) groups were clearly separated from each other.
\end{abstract}

Correspondence to: Professor Li Li, Department of Gynecologic Oncology, Affiliated Tumor Hospital of Guangxi Medical University, 71 Hedi Road, Nanning, Guangxi 530021, P.R. China E-mail: lili@gxmu.edu.cn

Key words: ovarian cancer, drug resistance, isobaric tags for relative and absolute quantitation, proteomics, metabolomics
Those findings may provide theoretical clues for the prediction of chemotherapeutic response and reverse of drug resistance, even lead to novel targets for therapeutic intervention.

\section{Introduction}

Ovarian cancer is the fifth leading cause of cancer deaths in women and has the highest overall mortality rate and poor 5-year survival. More than $90 \%$ of ovarian cancer cases are epithelial ovarian cancer (EOC), which represents a series of etiologically and molecularly distinct disease. Although early diagnosis and therapy are considered to be the most effective methods to improve the outcome of patients with any cancer, the majority of EOC patients often do not manifest clinical symptoms and receive medical intervention when their tumor cells have disseminated to the peritoneal cavity. Currently, the standard therapy for EOC is surgical resection followed by postoperative chemotherapy with carboplatin and paclitaxel (PTX). Despite initial responsiveness to cisplatin-based chemotherapy, surgical and chemotherapy is far from satisfactory and most patients eventually develop drug-resistant tumors and succumb to the recurrent disease. This is why the majority of EOC patients with advanced disease relapse within 5 years, and little progress has been made in improving overall survival rates. Previous studies have proposed numerous factors to influence drug-resistance, such as ATP-dependent efflux pumps, extracellular microenvironment, DNA repair mechanism, modification of the drug target, drug-induced cytotoxicity, disruptions in apoptotic signaling pathways and changes in the expression of protein associated with tumor resistance $(1,2)$. Cisplatin has been used to treat various cancers primarily by causing DNA damage and has been accepted worldwide as a first-line anticancer drug for EOC chemotherapy. In this regard, to identify those patients who have potential recurrence and to overcome chemoresistance and therefore improving patient outcome are the serious challenges in the management of EOC patients. Nevertheless, none of the identified biomarkers for drug resistance have been proven acceptable for routine clinical use. Hence, identification of clinical reliable biomarkers has come to the forefront of investigation. Moreover, if a non-invasive but sensitive blood assay that can monitor responses to chemotherapy was 
available, it would be invaluable for guiding chemotherapy and greatly improving the overall survival rate of EOC patients.

Mass spectrometry (MS) is an important high-throughput, industrially stable, information-rich technique for profiling small molecular compounds and is widely used to assess potential diagnostic and prognostic biomarkers. We applied isobaric tags for relative and absolute quantitation (iTRAQ)-based quantitative proteomic approach (Fig. 1A) and HPLC-micrOTOF-Q II high-resolution mass spectro-meter-based metabolic analysis to compare and identify proteins and metabolites with differential profile in normal control (NC) group, benign ovarian cyst (BOC), platinum-sensitive (PTS) and platinum-resistant(PTR) cohort of serum samples. The emergence of resistance to platinum-based therapy is the main clinical endpoint of this experiment. iTRAQ proteomic analysis that combines 2D-LC and MALDI-TOF-MS/MS is an established technique in which total proteins are enzymatically digested into a large array of small peptide fragments and then directly analyzed by liquid chromatography-mass spectro-metry (LC-MS). A total of 64 proteins with different expression levels were identified. In the list of differentially identified proteins via this method, most of these proteins were in accordance with the previously published literatures and associated with cancers. In addition, to further explore the new biomarkers predicting the responses to cisplatin, four of these proteins (FN1, SERPINA1, ORM1 and $G P X 3)$ were confirmed in a large patient cohort using western blotting and commercial enzyme-linked immunosorbent assay (ELISA), respectively. Moreover, HPLC-micrOTOF-Q II MS coupled with multivariate analysis was utilized, good separations were obtained for PTR, PTS vs. health controls. Finally, six substances with low molecular weight were identified based on the database using nuclear magnetic resonance (NMR). Receiver operating characteristic (ROC) curve analysis was then used to elucidate the potential power of FN1, SERPINA1, $O R M 1$ and six small molecular metabolites for discriminating between the PTS and PTR group. The findings of this study are expected to reveal new proteins and metabolites related to platinum resistance and to provide candidate biomarkers to predict clinical response to chemotherapy. However, we do need an effective serum marker to predict the patients who have no response to cisplatin chemotherapy and will progress or recur during or after chemotherapy that cannot be easily judged from ultrasound or CT scan. This prediction is fundamental since patients that are resistant might benefit from a different combinational chemotherapy.

\section{Materials and methods}

Human serum samples. After Institutional Review Board approval (Ethics Committees of the Affiliated Tumor Hospital of Guangxi Medical University, Nanning, China), we obtained specimens (Table I) between September 1998 and March 2013 , including EOC and BOC specimens. EOC cases were assigned to the PTR and PTS group. The FIGO classification was used for clinical staging, and the Gynecologic Oncology Group criteria were used for histological grading. NC blood samples were voluntarily donated by healthy individuals. Patients were eligible to participate in this trial if they had a pathologically confirmed diagnosis of BOC or EOC. After giving informed consent, serum samples were collected by clean venipuncture, centrifuged for $10 \mathrm{~min}$ at $3,000 \mathrm{x} \mathrm{g}$ at $4^{\circ} \mathrm{C}$ and stored at $-80^{\circ} \mathrm{C}$ until further analysis.

Chemicals and reagents. The iTRAQ ${ }^{\mathrm{TM}}$ Reagent kit and mass calibration standards were purchased from Applied Biosystems (Bedford, MA, USA). Sequencing grade trypsin was obtained from Promega (Madison, WI, USA). Amicon Ultra-15 Certifugal Filter Units (3 kDa) were purchased from EMD Millipore (Billerica, MA, USA). All the solvents and chemicals used in this experiment were of LC-MS or analytical grade. HPLC grade water and acetonitrile (ACN) were purchased from Merck KGaA (Darmstadt, Germany). BCA assay kit was purchased from Pierce Biotechnology, Inc. (Rockford, IL, USA). Methyl methanethiosulfonate (MMTS) and methanol were obtained from Thermo Fisher Scientific (Rockford, IL, USA). Triethylammonium bicarbonate (TEAB), trifluoroacetic acid (TFA), formic acid and $\alpha$-cyano-4-hydroxycinnamic acid (CHCA) were all obtained from Sigma (St. Louis, MO, USA).

\section{Proteomic analysis}

Depletion of high abundant proteins. Pooled serum samples were depleted of the 14 most highly abundant proteins using antibody-based depletion with Human 14 Multiple Affinity Removal System (MARS Hu-14; Agilent Technologies, Inc., Palo Alto, CA, USA), according to the manufacturer's instructions. Crude serum samples were thawed on ice. Equal amounts of blood $(20 \mu \mathrm{l})$ from 10 individuals in each group were pooled. Thereafter, MARS Hu-14 column was used to deplete specific 14 high-abundant proteins $\sim 94 \%$ of total protein mass from human serum (Fig. 1B). The total protein concentrations of the depleted sera were determined using the BCA Protein Assay Reagent Kit (Pierce Biotechnology, Inc.) (Fig. 1C).

iTRAQ labeling. Prior to iTRAQ analysis, aliquots of $100 \mu \mathrm{g}$ protein from each of the four sample pools were reduced using dissolution buffer (0.5 M TEAB) to a volume of $20 \mu \mathrm{l}$. To each of the four pools, $1 \mu \mathrm{l}$ denaturant ( $2 \%$ SDS) and $2 \mu \mathrm{l}$ reducing reagent [50 $\mathrm{mM}$ tris(2-carboxyethyl)phosphine] were added. Each pool was incubated at $60^{\circ} \mathrm{C}$ for $1 \mathrm{~h}$. Cysteines were stopped by adding $1 \mu \mathrm{l}$ cystine-blocking reagent (200 mM MMTS in isopropanol), and samples were incubated for additional $10 \mathrm{~min}$ at room temperature. The samples were digested with Sequencing Grade Modified Trypsin (Promega) at a protein-to-trypsin ratio of $30: 1$, at $37^{\circ} \mathrm{C}$ overnight. After that, peptides from each of the four depleted serum pools were labeled with 8-plex iTRAQ reagents (AB SCIEX, Foster City, CA, USA) according to the manufacturer's instructions. The labels were applied in the following order: NC pool (113 Da), BOC pool (114 Da), PTS pool (115 Da); PTR pool (116 Da), so as to run the same sample in duplicate in each run. The four labeled samples were then evaporated to a volume of roughly $30 \mu \mathrm{l}$ using a SpeedVac Concentrator and combined as a mixture followed by cleaning up by a strong cation exchange (SCX) column.

2D-LC-ESI-MS/MS. The combined peptide sample was subjected to SCX chromatography employing a PolySulfoethyl A column (2.1x200 nm; PolyLC, Inc., Columbia, MD, USA), on a high-pressure LC-pump (1200 series; Agilent Technologies, Inc.). The mixed sample was diluted in $10 \mathrm{mM}$ 
Table I. Clinical characteristics of 40 cases of samples used in screening, 129 cases in validating and 132 samples in comparing metabolomic profiles between NC, BOC, PTS and PTR groups.

\begin{tabular}{|c|c|c|c|c|c|}
\hline Clinical characteristics & $\mathrm{NC}$ & $\mathrm{BOC}$ & PTS & PTR & $\mathrm{P}$-value \\
\hline \multicolumn{6}{|l|}{ iTRAQ $(n=40)$} \\
\hline No. of patients & 10 & 10 & 10 & 10 & - \\
\hline iTRAQ-labeled sample & $\begin{array}{l}113(\operatorname{run} 1) \\
117(\operatorname{run} 2)\end{array}$ & $\begin{array}{l}114(\operatorname{run} 1) \\
118(\operatorname{run} 2)\end{array}$ & $\begin{array}{l}115(\text { run } 1) \\
119(\text { run } 2)\end{array}$ & $\begin{array}{l}116(\operatorname{run} 1) \\
121(\operatorname{run} 2)\end{array}$ & $\begin{array}{l}- \\
-\end{array}$ \\
\hline Age (years) $($ mean $\pm S D)$ & $39.80 \pm 5.53$ & $44.1 \pm 18.11$ & $47.21 \pm 12.64$ & $44.85 \pm 16.17$ & - \\
\hline \multicolumn{6}{|l|}{ Histological type } \\
\hline Serous & - & $6 / 10$ & $4 / 10$ & $6 / 10$ & - \\
\hline Mucinous & - & $2 / 10$ & $2 / 10$ & $1 / 10$ & - \\
\hline Other & - & $2 / 10$ & $4 / 10$ & $3 / 10$ & - \\
\hline \multicolumn{6}{|l|}{ FIGO stage } \\
\hline I-II & - & - & $3 / 10$ & $3 / 10$ & - \\
\hline III-IV & - & - & $7 / 10$ & $7 / 10$ & - \\
\hline \multicolumn{6}{|l|}{ Tumor grade } \\
\hline Well-differentiated & - & - & $1 / 10$ & $2 / 10$ & - \\
\hline Moderately-differentiated & - & - & $1 / 10$ & $1 / 10$ & - \\
\hline Poorly-differentiated & - & - & $8 / 10$ & $7 / 10$ & - \\
\hline \multicolumn{6}{|l|}{ ELISA $(n=129)$} \\
\hline No. of patients & 33 & - & 52 & 44 & - \\
\hline Age (years) $($ mean $\pm S D)$ & $39.71 \pm 10.05$ & - & $46.33 \pm 10.65$ & $47.08 \pm 10.85$ & - \\
\hline \multicolumn{6}{|l|}{ Histological type } \\
\hline Serous & - & - & $26 / 52$ & $17 / 44$ & - \\
\hline Mucinous & - & - & $7 / 52$ & $6 / 44$ & - \\
\hline Other & - & - & $19 / 52$ & $21 / 44$ & - \\
\hline \multicolumn{6}{|l|}{ TNM stage } \\
\hline I-II & - & - & $19 / 52$ & $2 / 44$ & - \\
\hline III-IV & - & - & $33 / 52$ & $42 / 44$ & - \\
\hline \multicolumn{6}{|l|}{ Tumor grade } \\
\hline Well-differentiated & - & - & $14 / 52$ & $7 / 44$ & - \\
\hline Moderately-differentiated & - & - & $9 / 52$ & $10 / 44$ & - \\
\hline Poorly-differentiated & - & - & $29 / 52$ & $27 / 44$ & - \\
\hline FN1 $($ mean $\pm \mathrm{SD})$ & $69.14 \pm 13.29$ & - & $62.41 \pm 12.78$ & $71.08 \pm 13.19$ & 0.004 \\
\hline$O R M 1($ mean $\pm \mathrm{SD})$ & $157.43 \pm 18.26$ & - & $173.64 \pm 22.69$ & $221.12 \pm 34.60$ & 0.000 \\
\hline SERPINAI $($ mean $\pm \mathrm{SD})$ & $756.19 \pm 244.39$ & - & $685.69 \pm 204.59$ & $816.26 \pm 245.53$ & 0.021 \\
\hline \multicolumn{6}{|l|}{ Metabolomics $(n=132)$} \\
\hline No. of patients & 41 & 9 & 45 & 37 & - \\
\hline Age $($ years $)($ mean $\pm S D)$ & $39.61 \pm 9.25$ & $42.56 \pm 15.44$ & $46.56 \pm 10.03$ & $47.41 \pm 12.46$ & - \\
\hline \multicolumn{6}{|l|}{ Histological type } \\
\hline Serous & - & - & $23 / 45$ & $11 / 37$ & - \\
\hline Mucinous & - & - & $6 / 45$ & $4 / 37$ & - \\
\hline Other & - & - & $14 / 45$ & $19 / 37$ & - \\
\hline NA & - & - & $2 / 45$ & $3 / 37$ & - \\
\hline \multicolumn{6}{|l|}{ FIGO stage } \\
\hline I-II & - & - & $13 / 45$ & $3 / 37$ & - \\
\hline III-IV & - & - & $31 / 45$ & $32 / 37$ & - \\
\hline NA & - & - & $1 / 45$ & $2 / 37$ & - \\
\hline \multicolumn{6}{|l|}{ Tumor grade } \\
\hline Well-differentiated & - & - & $6 / 45$ & $3 / 37$ & - \\
\hline Moderately-differentiated & - & - & $5 / 45$ & $4 / 37$ & - \\
\hline
\end{tabular}


Table I. Continued.

\begin{tabular}{|c|c|c|c|c|c|}
\hline Clinical characteristics & $\mathrm{NC}$ & $\mathrm{BOC}$ & PTS & PTR & P-value \\
\hline Poorly-differentiated & - & - & $27 / 45$ & $20 / 37$ & - \\
\hline NA & - & - & $7 / 45$ & $10 / 37$ & - \\
\hline \multicolumn{6}{|l|}{ Primary therapy outcome } \\
\hline Success & - & - & $22 / 45$ & $13 / 37$ & - \\
\hline $\mathrm{CR}+\mathrm{PR}$ & - & - & $21 / 45$ & $23 / 37$ & - \\
\hline $\mathrm{SD}+\mathrm{PD}$ & - & - & $2 / 45$ & $1 / 37$ & - \\
\hline NA & & & & & \\
\hline
\end{tabular}

NC, normal control; BOC, benign ovarian cyst; PTS, platinum-sensitive; PTR, platinum-resistant; iTRAQ, isobaric tags for relative and absolute quantitation; ELISA, enzyme-linked immunosorbent assay; NA, not available.

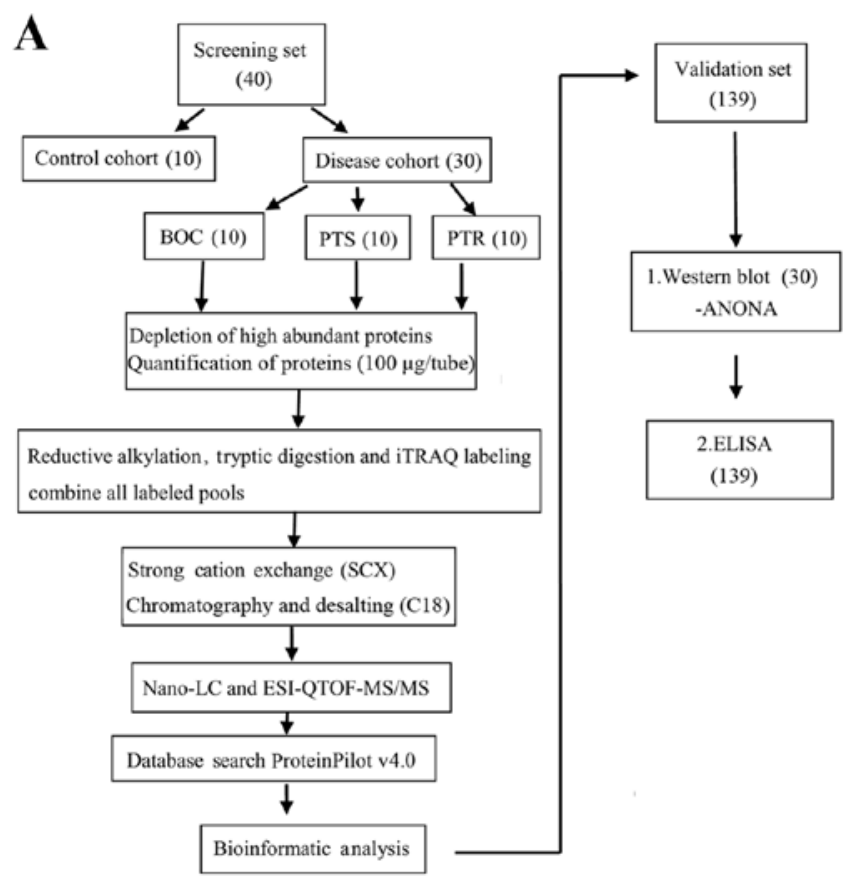

B

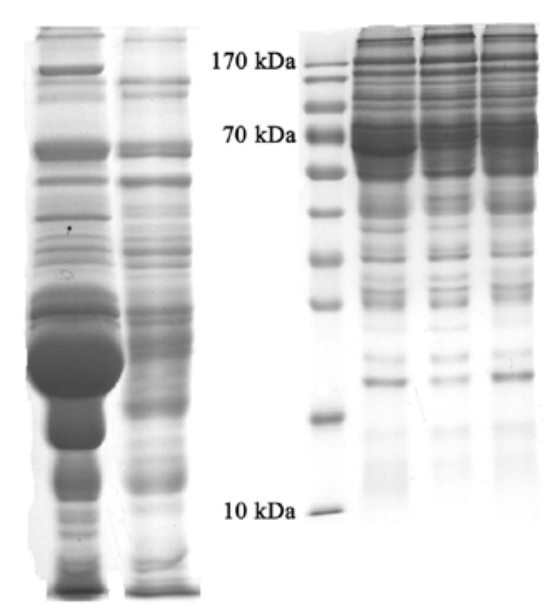

Figure 1. (A) Overall workflow for screening and validation experiments. (B) Comparison of human serum after depletion of the targeted high abundant proteins. Samples were separated by $10 \%$ SDS-PAGE and visualized by Coomassie Brilliant Blue staining: lane 1, human crude serum; lane 2, low-abundant proteins. (C) Equal amounts of the depleted sera from NC, PTS, and PTR individuals were loaded in each lane, according to the concentrations determined by the BCA kit. NC, normal control; PTS, platinum-sensitive; PTR, platinum-resistant.

$\mathrm{KH}_{2} \mathrm{PO}_{4}$ (pH 3.0), 25\% v/v ACN (mobile phase A). Peptides were eluted with a linear gradient of 0-500 $\mathrm{mM} \mathrm{KCl}$ (mobile

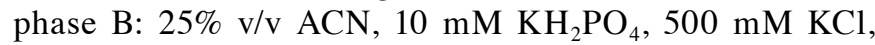
$\mathrm{pH} 3.0$ ) for $115 \mathrm{~min}$ at a flow rate of $0.2 \mathrm{ml} / \mathrm{min}$. Fractions were collected at 2-min intervals, and 16 fractions were collected from 24.5 to $98.5 \mathrm{~min}$. Each SCX fraction was desalted using C18 Spin Columns (The Nest Group, Inc., Southborough, MA, USA) following the manufacturer's instructions and then vacuum centrifuged to dryness. The peptide fractions were separated on a nano-reverse-phase LC system $\left(\mathrm{Tempo}^{\mathrm{TM}}\right.$ LC MALDI Spotting System; Applied Biosystems), using a Magic C18AQ column (150 mm x $200 \mu \mathrm{m}, 3 \mu \mathrm{m}, 200 \AA$; Michrom Bioresources, Inc., Auburn, CA, USA), at a flow rate of $2 \mu \mathrm{l} / \mathrm{min}$. A binary gradient with buffer A $\left(98 \% \mathrm{H}_{2} \mathrm{O}, 2 \%\right.$ ACN, and $0.1 \%$ TFA) and buffer $\mathrm{B}\left(2 \% \mathrm{H}_{2} \mathrm{O}, 98 \% \mathrm{ACN}\right.$, and $0.1 \%$ TFA) was employed as the mobile phase. The peptide solutions were first loaded for 20 min using buffer A only on the pre-column, and the separation occurred over a period of $110 \mathrm{~min}$. The elution from the column was mixed in 1:1 ratio with $5 \mathrm{mg} / \mathrm{ml} \mathrm{CHCA}$ with a flow rate of $2 \mu \mathrm{l} / \mathrm{min}$, and spotted onto the MALDI plates in a $44 \times 28$ spot array format. MS and MS/MS analysis was performed on a TOF-TOF 5800 MALDI platform (Applied Biosystems). MS spectra were recorded in the positive-ion reflector mode covering 700/800-4000 mass-to-charge ratio (m/z) acquiring 1,500 laser shots per spectrum (30 subspectra of 50 shots). After screening of all LC-MALDI sample positions the fragmentation of automatically selected precursors was performed at a collision energy of $2 \mathrm{kV}$ with collision-induced dissociation gas (air). Up to 20 of the most intense ion signals per spot position, characterized by an $\mathrm{S} / \mathrm{N}>45$, were selected as precursors for MS/MS acquisition. 
A

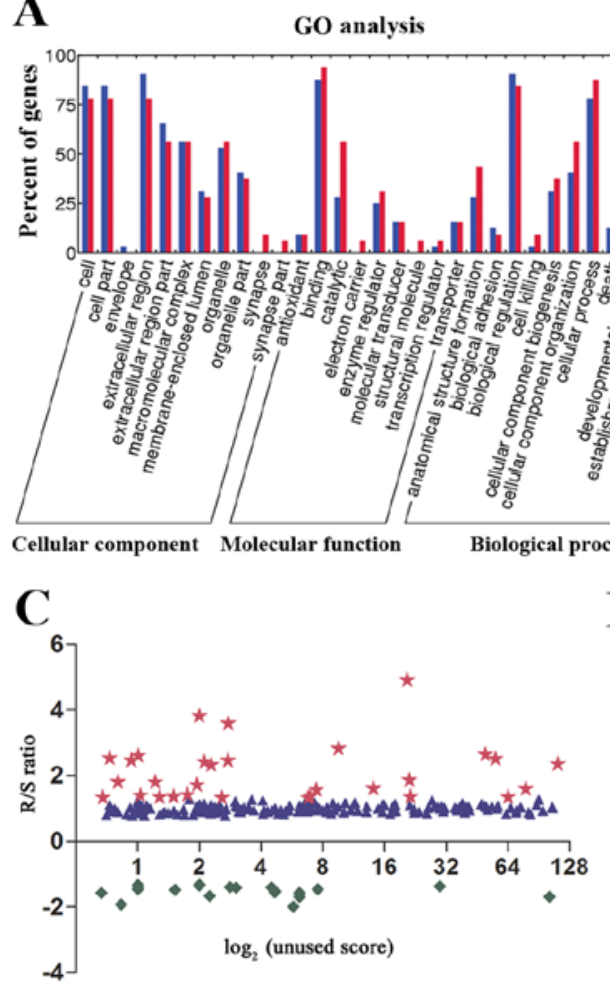

B
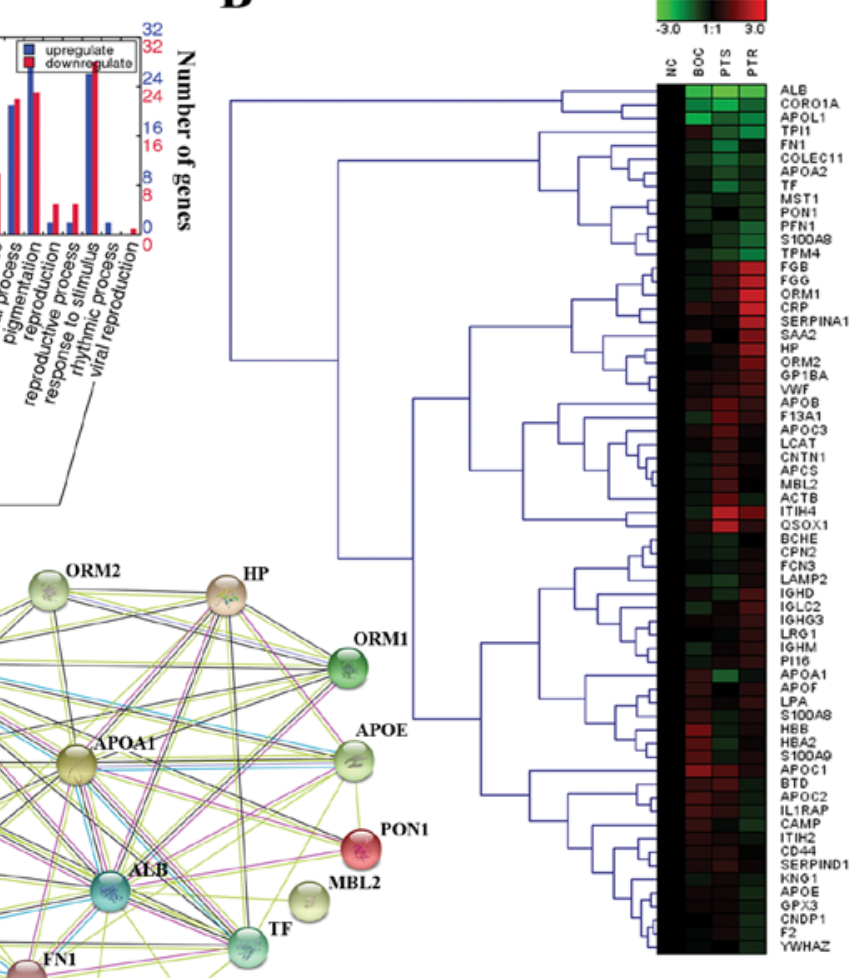

$\mathbf{E}$

F
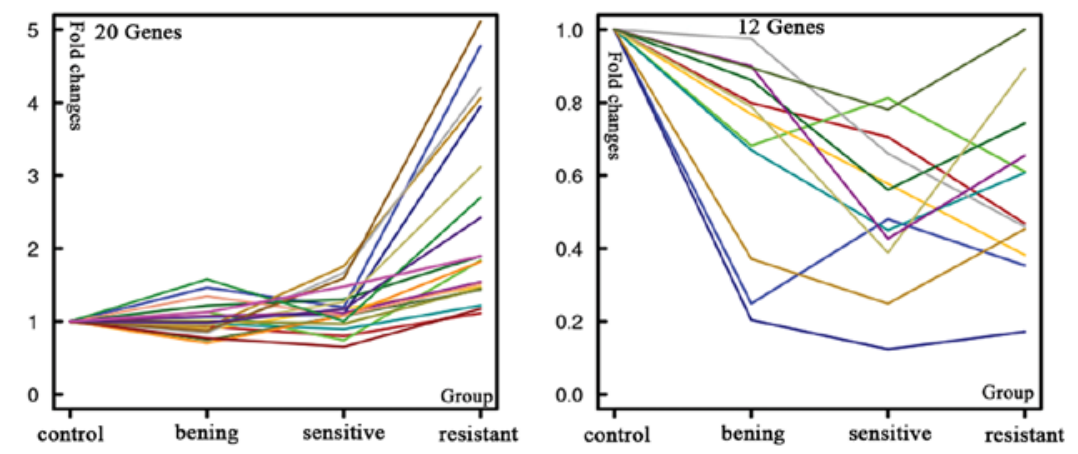

우을

G
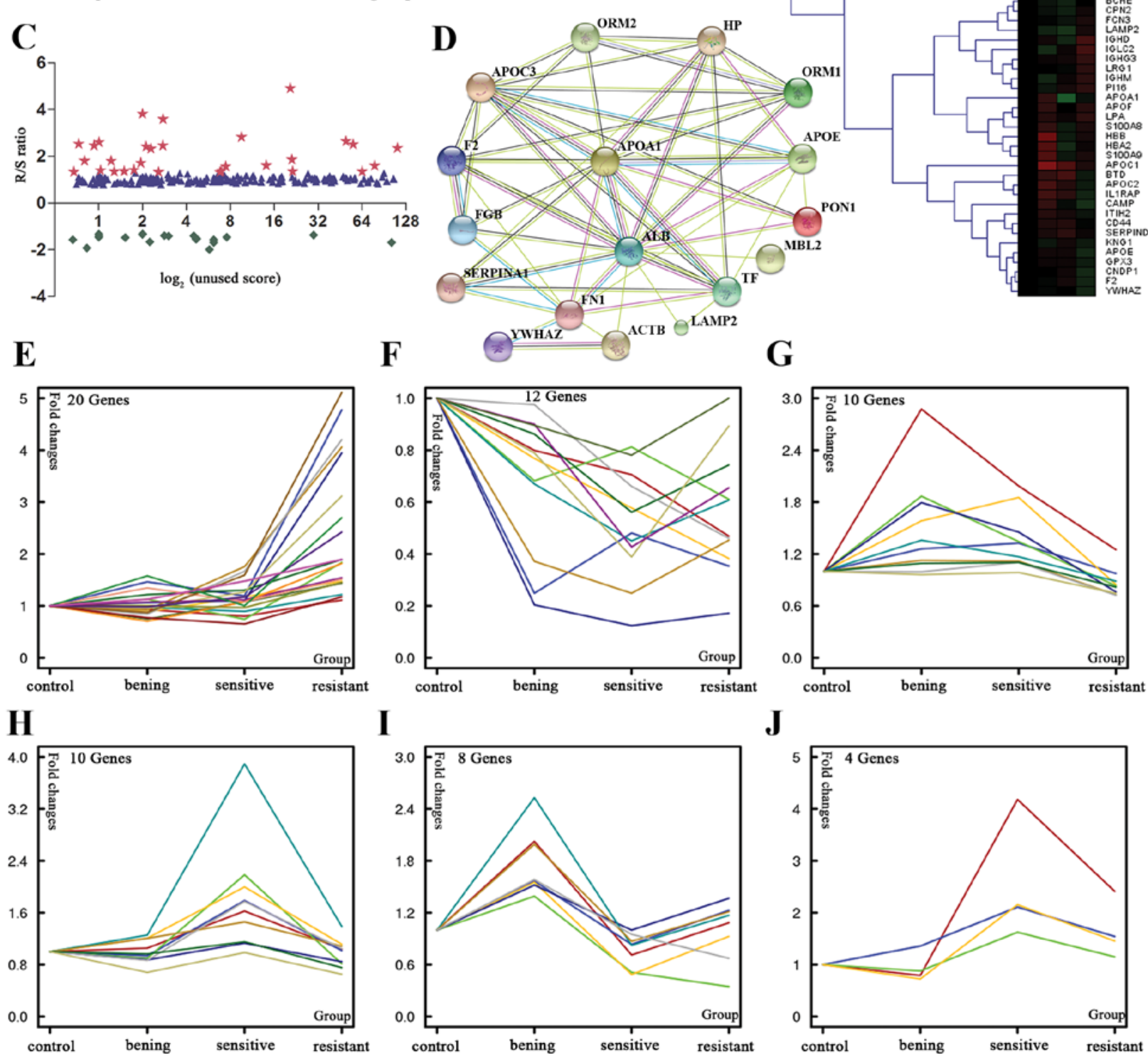

$\mathbf{J}$
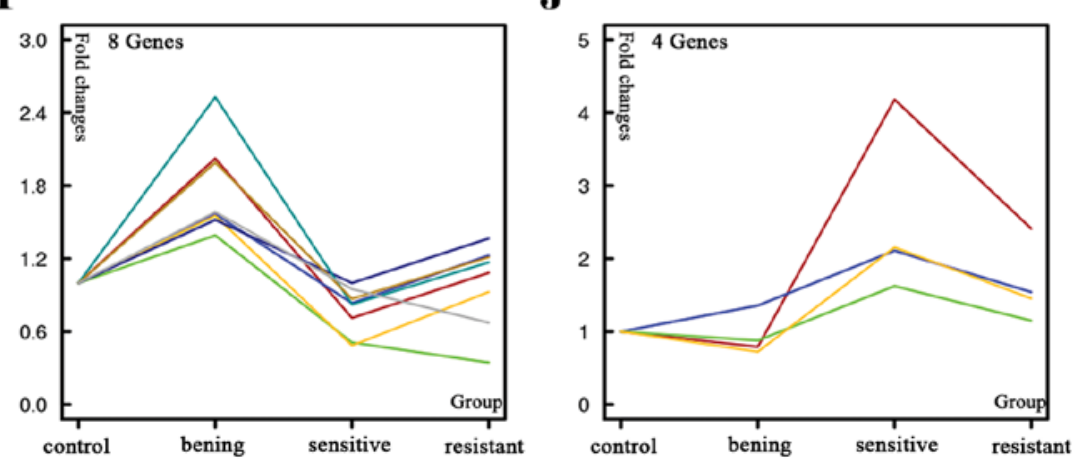

Figure 2. (A) Analysis of the 64 differential proteins between PTS and PTR group showing cellular component, molecular function and biological process. (B) Hierarchical clustering analysis representation of the altered serum protein profiles identified in PTS and PTR patients using a shotgun quantitative proteomic approach. Red, overexpressed genes; green, underexpressed genes. (C) Logarithmic plot of unused score of proteins in PTS vs. PTR pools. Red pentagrams, green diamonds and blue triangles denote R/S ratio $>1.3$-folds, $<0.77$-folds, and between them, respectively. (D) Biological interaction network analysis of proteins that showed differential abundance between PTS and PTR patients. (E-J) k-means clustering of differential protein profiles. The cluster gene number is labeled in the upper-left corner of each figure. Each line in the charts represents one differentially expressed protein. The shape of the line reveals the trend of differential expressed proteins in four groups. PTS, platinum-sensitive; PTR, platinum-resistant.

Database searches and criteria. Peptide matching, protein identification, and relative protein quantification for the
iTRAQ experiment were performed with ProteinPilot v4.0 software (Applied Biosystems) in which the paragon search 
Table II. Differentially expressed proteins identified by iTRAQ between PTR group compared to PTS group.

\begin{tabular}{|c|c|c|c|c|c|c|c|c|}
\hline \multirow{2}{*}{$\begin{array}{l}\text { Unused } \\
\text { protein } \\
\text { score }\end{array}$} & \multirow{2}{*}{$\begin{array}{c}\text { Sequence } \\
\text { coverage } \\
(\%)\end{array}$} & \multirow{2}{*}{$\begin{array}{l}\text { Accession } \\
\text { no. }\end{array}$} & \multirow[b]{2}{*}{ Name } & \multirow{2}{*}{$\begin{array}{c}\text { Gene } \\
\text { symbol }\end{array}$} & \multirow[b]{2}{*}{ Species } & \multicolumn{2}{|c|}{ iTRAQ ratio } & \multirow{2}{*}{$\begin{array}{l}\text { Expression } \\
\text { pattern }\end{array}$} \\
\hline & & & & & & Run 1 & Run 2 & \\
\hline 13.01 & 47.80 & P02763 & $\alpha$-1-acid glycoprotein 1 & $O R M 1^{\mathrm{a}}$ & Human & 3.32 & 2.34 & $\mathrm{Up}$ \\
\hline 4.56 & 41.80 & P19652 & $\alpha$-1-acid glycoprotein 2 & $O R M 2^{\mathrm{a}}$ & Human & - & 2.33 & Up \\
\hline 8.52 & 46.50 & D1MGQ2 & $\alpha-2$ globin chain & $H B A 2$ & Human & 1.58 & 1.56 & Up \\
\hline 23.74 & 72.70 & P02647 & Apolipoprotein A-I & $A P O A 1^{\mathrm{a}}$ & Human & 2.00 & 1.72 & Up \\
\hline 3.52 & 68.00 & P02652 & Apolipoprotein A-II & APOA2 & Human & 1.33 & - & Up \\
\hline 2.99 & 23.60 & Q13790 & Apolipoprotein F & $A P O F$ & Human & 1.36 & - & Up \\
\hline 2.00 & 30.00 & P08519 & Apolipoprotein(a) & $L P A$ & Human & - & 1.57 & Up \\
\hline 19.91 & 35.80 & P22792 & Carboxypeptidase $N$ subunit 2 & CPN2 & Human & - & 1.45 & Up \\
\hline 8.27 & 30.10 & P06276 & Cholinesterase & $B C H E^{\mathrm{a}}$ & Human & - & 1.31 & Up \\
\hline 1.60 & 25.20 & P31146 & Coronin-1A & COROIA & Human & 1.81 & - & Up \\
\hline 1.86 & 35.30 & Q5VVP7 & $C$-reactive protein, pentraxin-related & $C R P$ & Human & 3.82 & 2.46 & Up \\
\hline 17.63 & 55.50 & E9KL23 & $\begin{array}{l}\text { Epididymis secretory sperm binding } \\
\text { protein } \mathrm{Li} 44 \mathrm{a}\end{array}$ & SERPINA $1^{\mathrm{a}}$ & Human & 6.02 & 3.80 & Up \\
\hline 4.23 & 44.00 & P02675 & Fibrinogen $\beta$ chain & $F G B^{\mathrm{a}}$ & Human & 2.42 & - & Up \\
\hline 111.13 & 54.60 & P02751 & Fibronectin & FN1 & Human & 2.52 & - & Up \\
\hline 16.43 & 55.20 & O75636 & Ficolin-3 & $F C N 3$ & Human & - & 1.37 & Up \\
\hline 63.09 & 79.10 & P00738 & Haptoglobin & $H P^{\mathrm{a}}$ & Human & 2.71 & 2.59 & $\mathrm{Up}$ \\
\hline 18.65 & 84.40 & D9YZU5 & Hemoglobin, $\beta$ & $H B B^{\mathrm{a}}$ & Human & 1.76 & 1.46 & Up \\
\hline 1.46 & 14.30 & P01880 & Ig $\delta$ chain $C$ region & $I G H D$ & Human & - & 2.54 & Up \\
\hline 2.03 & 39.30 & P01860 & Ig $\gamma-3$ chain $C$ region & $I G H G 3$ & Human & 1.36 & 1.47 & Up \\
\hline 3.89 & 51.90 & P0CG05 & Ig $\lambda-2$ chain $C$ regions & $I G L C 2$ & Human & - & 1.72 & Up \\
\hline 13.88 & 41.20 & P01871 & Ig $\mu$ chain $C$ region & $I G H M$ & Human & - & 1.37 & Up \\
\hline 224.13 & 70.60 & P02751-8 & Isoform 8 of fibronectin & $F N 1^{\text {a }}$ & Human & - & 2.35 & Up \\
\hline 1.35 & 43.70 & Q9BWP8-9 & Isoform 9 of collectin-11 & COLEC11 & Human & 1.34 & - & Up \\
\hline 25.71 & 70.90 & $\mathrm{P} 02750$ & Leucine-rich $\alpha$-2-glycoprotein & $L R G 1$ & Human & - & 1.55 & Up \\
\hline 2.43 & 19.00 & Q6Q3G8 & $\begin{array}{l}\text { Lysosomal-associated membrane } \\
\text { protein 2, isoform } C R A \_b\end{array}$ & $L A M P 2^{\mathrm{a}}$ & Human & 1.81 & - & Up \\
\hline 2.23 & 6.70 & Q6UXB8 & Peptidase inhibitor 16 & PI16 & Human & - & 1.30 & Up \\
\hline 2.56 & 47.40 & P06702 & Protein S100A9 & $S 100 A 9^{\mathrm{a}}$ & Human & 1.36 & - & Up \\
\hline 94.91 & 82.10 & P02787 & Serotransferrin & $T F^{\mathrm{a}}$ & Human & 1.63 & 1.58 & Up \\
\hline 75.06 & 73.60 & P02768 & Serum albumin & $A L B^{\mathrm{a}}$ & Human & - & 1.50 & Up \\
\hline 3.27 & 70.00 & E9PR14 & Serum amyloid A protein & $S A A 2$ & Human & 4.57 & 2.63 & Up \\
\hline 2.04 & 17.80 & E7ES66 & Uncharacterized protein & $G P 1 B A$ & Human & 1.50 & - & Up \\
\hline 5.51 & 37.80 & B4E1D3 & Uncharacterized protein & $F G B$ & Human & - & 2.46 & Up \\
\hline 2.01 & 20.40 & C9JC84 & Uncharacterized protein & $F G G$ & Human & - & 2.60 & Up \\
\hline 8.99 & 21.90 & $\mathrm{P} 04275$ & von Willebrand factor & $V W F^{\mathrm{a}}$ & Human & - & 1.33 & Up \\
\hline 499.38 & 71.20 & P04114 & Apolipoprotein B-100 & $A P O B^{\mathrm{a}}$ & Human & - & 0.74 & Down \\
\hline 3.82 & 61.50 & B2R526 & Apolipoprotein C-I & APOCl & Human & 0.63 & - & Down \\
\hline 6.00 & 65.40 & P02655 & Apolipoprotein C-II & APOC2 & Human & 0.62 & 0.68 & Down \\
\hline 7.18 & 61.50 & B0YIW2 & Apolipoprotein $C$-III variant 1 & $A P O C 3^{\mathrm{a}}$ & Human & 0.60 & 0.58 & Down \\
\hline 23.95 & 77.30 & P02649 & Apolipoprotein E & $A P O E^{\mathrm{a}}$ & Human & - & 0.60 & Down \\
\hline 8.96 & 43.20 & Q96KN2 & $\beta$-Ala-His dipeptidase & $C N D P 1$ & Human & - & 0.71 & Down \\
\hline 2.01 & 30.60 & P49913 & Cathelicidin antimicrobial peptide & $C A M P$ & Human & 0.71 & - & Down \\
\hline 4.00 & 21.70 & P00488 & Coagulation factor XIII A chain & $F 13 A 1^{\text {a }}$ & Human & 0.75 & 0.67 & Down \\
\hline 2.60 & 21.90 & Q12860 & Contactin-1 & $C N T N 1^{\mathrm{a}}$ & Human & 0.72 & - & Down \\
\hline 2.10 & 22.60 & $\mathrm{P} 22352$ & Glutathione peroxidase 3 & $G P X 3^{\mathrm{a}}$ & Human & - & 0.76 & Down \\
\hline 5.52 & 43.20 & Q1KLZ0 & HCG15971, isoform CRA_a & $P S 1 T P 5 B P 1^{\mathrm{a}}$ & Human & 0.62 & 0.39 & Down \\
\hline 50.43 & 70.10 & P05546 & Heparin cofactor II & SERPIND1 & Human & - & 0.76 & Down \\
\hline 3.78 & 31.50 & P26927 & Hepatocyte growth factor-like protein & MST1 & Human & 0.75 & - & Down \\
\hline 110.79 & 52.90 & P19823 & $\begin{array}{l}\text { Inter- } \alpha \text {-trypsin inhibitor } \\
\text { heavy chain } \mathrm{H} 2\end{array}$ & $I T I H 2^{\mathrm{a}}$ & Human & - & 0.77 & Down \\
\hline
\end{tabular}


Table II. Continued.

\begin{tabular}{|c|c|c|c|c|c|c|c|c|}
\hline \multirow{2}{*}{$\begin{array}{l}\text { Unused } \\
\text { protein } \\
\text { score }\end{array}$} & \multirow{2}{*}{$\begin{array}{c}\text { Sequence } \\
\text { coverage } \\
(\%)\end{array}$} & \multirow{2}{*}{$\begin{array}{l}\text { Accession } \\
\text { no. }\end{array}$} & \multirow[b]{2}{*}{ Name } & \multirow{2}{*}{$\begin{array}{l}\text { Gene } \\
\text { symbol }\end{array}$} & \multirow[b]{2}{*}{ Species } & \multicolumn{2}{|c|}{ iTRAQ ratio } & \multirow{2}{*}{$\begin{array}{l}\text { Expression } \\
\text { pattern }\end{array}$} \\
\hline & & & & & & Run 1 & Run 2 & \\
\hline 1.66 & 14.60 & Q9NPH3 & Interleukin-1 receptor accessory protein & ILIRAP & Human & 0.52 & - & Down \\
\hline 2.00 & 36.20 & O14791-2 & Isoform 2 of apolipoprotein L1 & APOL1 & Human & - & 0.76 & Down \\
\hline 4.00 & 19.20 & $\mathrm{P} 16070-5$ & Isoform 5 of CD44 antigen & $C D 44^{\mathrm{a}}$ & Human & 0.74 & - & Down \\
\hline 204.25 & 80.80 & B7ZKJ8 & ITIH4 protein & ITIH4 & Human & - & 0.59 & Down \\
\hline 44.35 & 54.80 & P01042 & Kininogen-1 & $K N G 1^{\text {a }}$ & Human & 0.77 & - & Down \\
\hline 8.29 & 43.20 & Q5SQS3 & Mannan-binding lectin & $M B L 2^{\mathrm{a}}$ & Human & 0.69 & 0.59 & Down \\
\hline 1.33 & 11.80 & P04180 & $\begin{array}{l}\text { Phosphatidylcholine-sterol } \\
\text { acyltransferase }\end{array}$ & $L C A T$ & Human & 0.64 & - & Down \\
\hline 2.00 & 13.60 & Q53Y44 & Profilin & PFN1 & Human & - & 0.68 & Down \\
\hline 99.83 & 76.50 & P00734 & Prothrombin & $F 2^{\mathrm{a}}$ & Human & - & 0.65 & Down \\
\hline 21.20 & 60.10 & $\mathrm{P} 02743$ & Serum amyloid $P$ component & $A P C S$ & Human & - & 0.58 & Down \\
\hline 9.43 & 27.90 & P27169 & Serum paraoxonase/arylesterase 1 & $P O N 1^{\text {a }}$ & Human & 0.66 & - & Down \\
\hline 2.00 & 17.70 & O00391 & Sulfhydryl oxidase 1 & $Q S O X 1^{\mathrm{a}}$ & Human & - & 0.37 & Down \\
\hline 2.00 & 23.10 & D3DUS9 & Triosephosphate isomerase & $T P I 1^{\mathrm{a}}$ & Human & - & 0.70 & Down \\
\hline 3.05 & 51.60 & P67936 & Tropomyosin $\alpha-4$ chain & TPM4 & Human & - & 0.68 & Down \\
\hline 6.31 & 26.60 & A6NHF2 & Uncharacterized protein & $B T D$ & Human & 0.41 & - & Down \\
\hline 2.00 & 21.50 & E7EX29 & Uncharacterized protein & $Y W H A Z^{\mathrm{a}}$ & Human & 0.75 & - & Down \\
\hline
\end{tabular}

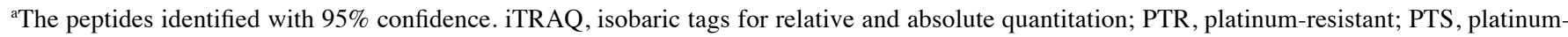
sensitive.

algorithm was applied. MS/MS spectra were searched against the UniProt/Swiss-Prot database for species of Homo sapiens. The database was searched using the following parameters: trypsin was used as the digestion agent, MMTS as a fixed modification of cysteine, thorough as search effort, and biological modification as the ID focus. Identifications of proteins were only accepted with a 'local false discovery rate (FDR)' estimation of $\leq 5 \%$ and an unused ProtScore $\geq 1.3$ ( $>95 \% \mathrm{CI}$ ). In addition, proteins were considered for further statistical analysis when meet the following standards: one or more unique peptides with $95 \%$ confidence had to be identified; proteins were considered up- or downregulated when their fold changes were $>1.3$ or $<0.77$. The results obtained from ProteinPilot were exported to Microsoft Excel for manual interpretation. The protein lists from the two iTRAQ experiments (run 1 and 2; Table II) were merged with ratios calculated to the reference pool.

Western blotting. To confirm the identity of the proteins discovered by iTRAQ, western blotting was performed (Fig. 3A-E). Briefly, equal volumes of non-depleted serum from NC, PTS and PTR individuals ( $\mathrm{n}=9$ per group) were electrophoretically separated by $10 \%$ SDS-PAGE and transferred to a $0.45-\mathrm{mm}$ polyvinylidene fluoride membranes (EMD Millipore) using a Bio-Rad wet transfer apparatus. Anti-human ORM1 $(2 \mu \mathrm{g} / \mathrm{ml})$, FN1 (1:1,000 dilution), SERPINA1 (1:1,000) and GPX3 (1:500) antibodies were from R\&D Systems, Inc. (cat. no. MAB3694), Sigma (cat. no. F3648), OriGene Technologies, Inc., (cat. no. TA500376) and Abcam (cat. no. ab27325). Secondary antibodies were DyLight 680 anti-mouse (cat. no. 072-06-18-06,
1:5,000 dilution; KPL, Inc.) and IRDye 680RD donkey anti-rabbit (cat. no. 926-32223, 1:5,000 dilution; LI-COR Biosciences). Membranes were blocked with 5\% skim milk in phosphate-buffered saline (PBS) with $0.1 \%$ Tween-20 for $2 \mathrm{~h}$ at room temperature. The concentration of primary and secondary antibodies was consistent as recommended in the instructions. Then membranes were incubated with primary antibodies overnight at $4{ }^{\circ} \mathrm{C}$, followed by fluorescent secondary antibodies $(1: 5,000)$ for $1 \mathrm{~h}$ at ambient temperature. After washing three times in PBST, proteins were detected with Odyssey infrared imaging system (LI-COR Biosciences, Lincoln, NE, USA) following the manufacturer's instructions.

ELISA. Based on the iTRAQ and western blotting findings above we selected four targets, SERPINA1, ORM1, GPX3 and $F N 1$, the protein markers potentially associated with PTR, for the validation using ELISA method. ORM1, FN1, SERPINA1 ELISA kits were obtained from and utilized according to the manufacture's instructions. ORMI and FN1 serum samples were diluted 100-fold, and SERPINA1 serum samples were diluted 50-fold. All samples and standards were tested in triplicate. Absorbance was determined using Power Scan 4 multiplex microplate reader (DS Pharma Biomedical Co. Ltd., Osaka, Japan) and analysis of results was conducted by SPSS 16.0 software.

Statistical analysis. Statistical analyses were performed with SPSS 16.0 software (SPSS, Inc., Chicago, IL, USA). A comparative analysis of multiple groups was analyzed by one-way ANOVA or Kruskal-Wallis test and multiple 
A

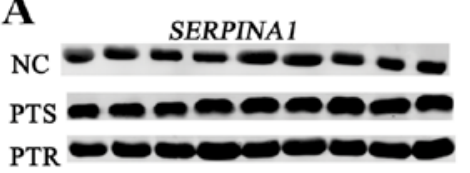

D
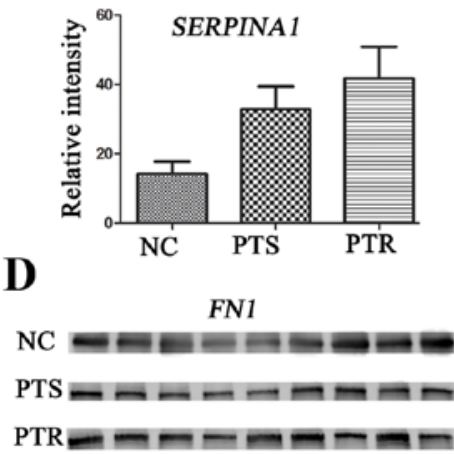

$\mathbf{F}$
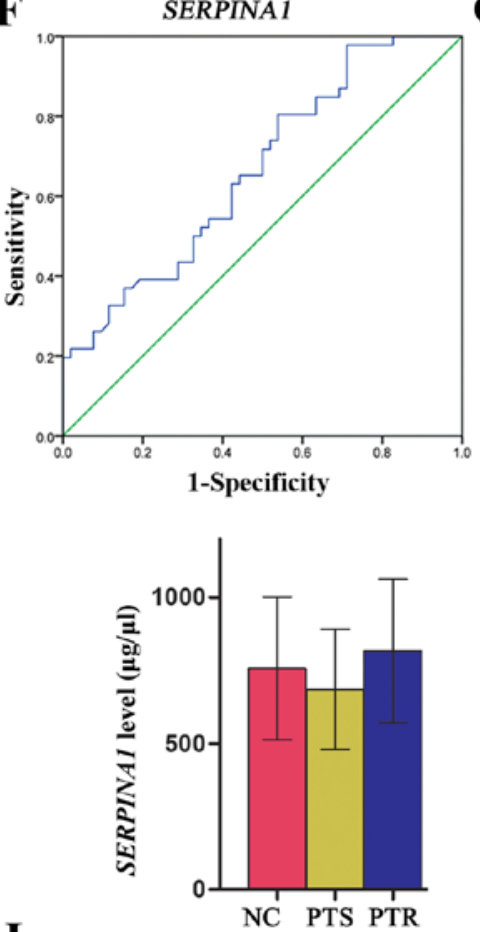

B

\section{$\mathrm{NC}$

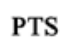 \\ PTR}
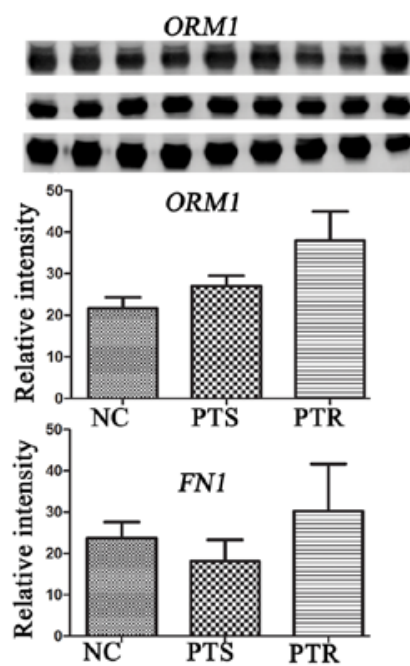

G
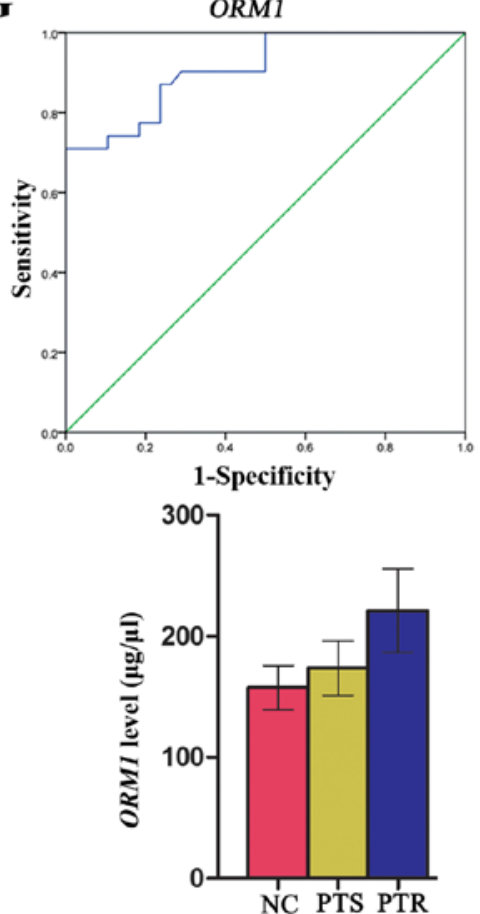

C
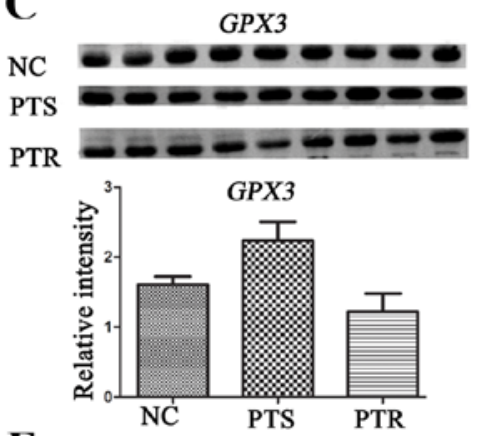

$\mathbf{E}$

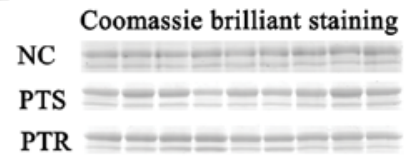

$\mathbf{H}$
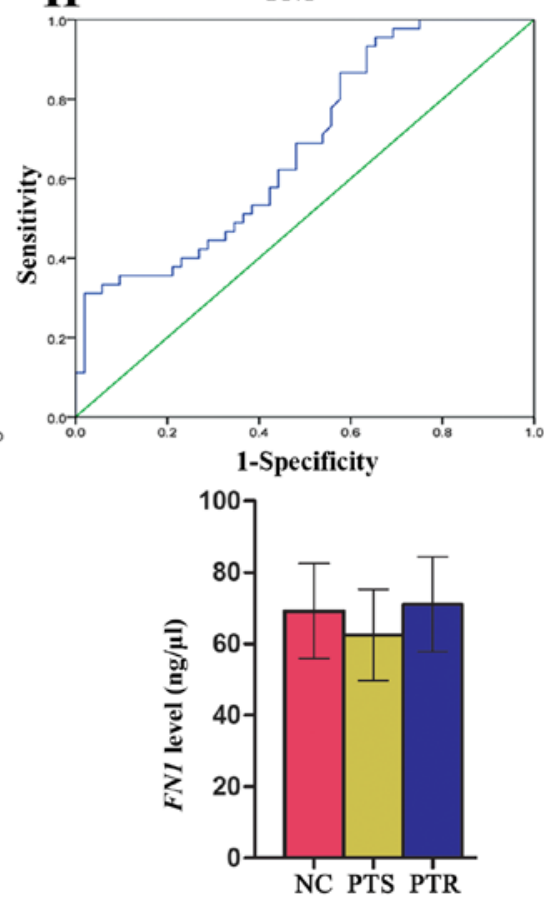

I

\begin{tabular}{cccccccc}
\hline Protein & AUC & Sensitivity & Specificity & Cut-off & Accuracy & PV+ & LR $(+)$ \\
\hline FN1 & 0.679 & 95.600 & 34.600 & 54.700 & 0.629 & 0.558 & -2.845 \\
ORM1 & 0.910 & 71.000 & 97.400 & 208.490 & 0.855 & 0.957 & -0.737 \\
SERPINA1 & 0.666 & 97.800 & 28.800 & 537.850 & 0.612 & 0.549 & -3.518 \\
\hline
\end{tabular}

Figure 3. (A-D) Western blotting of SERPINA1, ORM1, GPX3 and FN1 protein expressions in human serum. Western blotting was carried out using antibodies against SERPINA1, ORM1, GPX3 and FN1. Consistent with the proteomic results, the expressions of SERPINA1, ORM1 and FN1 were significantly upregulated $(\mathrm{p}<0.05)$, whereas, GPX3 protein expression was significantly downregulated $(\mathrm{p}<0.05)$ in PTR group, compared to the PTS group. (E) The overall protein profile of the NC, PTS and PTR groups. The gel was stained with Coomassie Brilliant Blue to ensure equal loadings during immunoblotting analysis. The expression levels of the four differential proteins were normalized based on the Coomassie Brilliant Blue staining. ${ }^{*} \mathrm{P}<0.05$. ROC curve analysis using the ELISA profile of the (F) SERPINA1, (G) ORM1 and (H) FN1 for the 129 sera analyzed. SPSS software was used to construct ROC curves and to calculate the AUC. The solid lines in the ROC curves represent the plot of 1-specificity vs. sensitivity. Histogram was used to elucidate the profile of ELISA. Mean \pm SD was used to express protein level. ${ }^{*} \mathrm{P}<0.05,{ }^{* *} \mathrm{p}<0.01$. (I) Clinical diagnostic performance of the three proteins in PTR and PTS groups. PTR, platinum-resistant; PTS, platinum-sensitive; NC, normal control; ROC, receiver operating characteristic; ELISA, enzyme-linked immunosorbent assay; AUC, area under the curve.

comparisons were performed with the least significant difference test. Results are presented as means $\pm \mathrm{SD}$. ROC curves were used to determine the diagnostic value of the markers. $\mathrm{P}<0.05$ was considered statistically significant.

\section{Metabolical analysis}

Serum sample preparation. Prior to serum preparation, samples were thawed on ice for $1 \mathrm{~h}$. A total of $200 \mu \mathrm{l}$ of serum (stored at $-80^{\circ} \mathrm{C}$ ) was resuspended with $800 \mu 1$ cold CAN (stored at 
$-20^{\circ} \mathrm{C}$ ) mixed thoroughly, and precipitated on ice for $2 \mathrm{~h}$. The samples were centrifuged at $4^{\circ} \mathrm{C}$ and $12,000 \mathrm{x}$ g for $15 \mathrm{~min}$. The supernatant was then transferred to a new tube. Subsequently, serums were lyophilized for $24 \mathrm{~h}$ using a freeze dryer (Beijing Songyuan Huaxing Biotechnology Co., Ltd., Beijing, China). Methanol $(200 \mu \mathrm{l})$ was added to lyophilized samples, vortexed, sonicated for $5 \mathrm{~min}$, and centrifuged $\left(12,000 \mathrm{x} \mathrm{g}, 4^{\circ} \mathrm{C}, 5 \mathrm{~min}\right)$. The supernatant $(150 \mu \mathrm{l})$ was collected for further analysis.

Metabolic signature via LC-MS.LC-MS analysis was performed using Agilent HPLC (1290 series) fitted with a Zorbax Rx-C8 column (5 $\mu \mathrm{m}, 150 \times 2.1 \mathrm{~mm}$; Agilent Technologies, Inc.) and coupled to a Bruker Daltonics' micrOTOF-Q II high-resolution mass spectrometer. The flow rate was $0.25 \mathrm{ml} / \mathrm{min}$, injection volume $5 \mu \mathrm{l}$ and column temperature $30^{\circ} \mathrm{C}$. The mobile phase was consisted of solvent A $(0.1 \%$ formic acid, $99.9 \%$ water $)$ and solvent $\mathrm{B}(0.1 \%$ formic acid, $99.9 \%$ ACN $)$. HPLC conditions were $15 \%$ solvent $\mathrm{B}$ changing linearly to $40 \%$ solvent $\mathrm{B}$ over $5 \mathrm{~min}$, to $80 \%$ solvent B over $10 \mathrm{~min}, 80 \%$ solvent B over $5 \mathrm{~min}$, to $90 \%$ solvent B over $5 \mathrm{~min}$, and then $90 \%$ solvent B over $15 \mathrm{~min}$. Finally, mobile phase constituents reverted to starting conditions for $5 \mathrm{~min}$ re-equilibration. Total analysis time was $45 \mathrm{~min}$. Mass spectral analysis was operated on a micrOTOF-Q II high-resolution mass spectrometer (Bruker Daltonics) linked to an Agilent HPLC (1290 series) by HyStar software (Bruker Daltonics). Electrospray ionization (ESI) (positive ion mode) was used to identify the molecular ion mass $[\mathrm{M}+\mathrm{H}]$. Source parameters are: ESI capillary voltage, 4,500 V; nebulizing gas pressure, 1 bar; drying gas flow, $6 \mathrm{l} / \mathrm{min}$; and drying gas temperature, $220^{\circ} \mathrm{C}$. Data were acquired in a mass range of $50-1,500 \mathrm{~m} / \mathrm{z}$.

Data analysis. Following LC-MS, raw MS data were converted into a matrix that is compatible with multivariate statistical analysis and interpretation by using an in-house set of tools, such as the Compass software package (Bruker Daltonics). Signals obtained from each sample in the chromatogram were segmented into a series of regions characterized by retention time and $\mathrm{m} / \mathrm{z}$ using the Compass software, furthermore, the theoretical $\mathrm{m} / \mathrm{z}$ values were compared with the experimental values from MS signals. Based on the exact $\mathrm{m} / \mathrm{z}$, elemental formulas were generated using the DataAnalysis software (Bruker Daltonics). C, H, N, O, P and S were the elements of the formulas. The lists of generated formulas were searched against the METLIN database (https://metlin.scripps.edu/) to identify compounds. Principal component analysis (PCA) was then operated utilizing Profile Analysis software (Compass software package; Bruker Daltonics).

\section{Results}

\section{Proteomic analysis}

Serum proteomic data analysis. To enhance the detection of the lower abundance proteins, most of the 14 abundant proteins were removed in equal volumes from each sample. Technical replicate samples were used to increase the reliability of the iTRAQ technique for relative quantitation. The relative expression levels, statistical parameters and the peptide information of identified proteins for each pool were obtained from two (replicate) peptide spectra data as described above.
Subsequently, all the identified proteins were filtered with manually selected filter exclusion parameters. Thus, in the first iTRAQ data set (run 1), identification of 197 proteins was made. Similarly, 184 proteins were discovered in the second iTRAQ data set (run 2). The proteins identified from the two iTRAQ data sets were subsequently combined, and a total of 248 unique proteins were identified and quantified. Proteins were considered up- or downregulated when their ratios were $>1.3$ or $<0.77$ (Fig. 2C). Therefore 64 proteins were screened out as candidate biomarkers in one or two separate experiments as differentially expressed proteins between PTS and PTR sets: 33 of which were increased (PTR/PTS >1.3) and 31 were decreased (PTR/PTS <0.77). Candidate biomarkers selected by these criteria are summarized in Table II. For better understanding of the data structure in our experiment, a clustering algorithm for grouping proteins was required (Fig. 2B), and $\mathrm{k}$-means clustering approach was then performed to group the data based on the degree of similarity between the PTS and PTR group. The different trends of identified proteins during PTS and PTR can be grouped into six subsets with a similar expression pattern (Fig. 2E). In the first subset, most of the 20 proteins were upregulated in a stepwise way in NC, BOC, PTS and PTR groups. Most are extracellular proteins involved in cell adhesion, cell communication and immune system process. The trend of these proteins differentially expressed in PTS and PTR groups were of interest as these could provide leads for potentially useful biomarkers of platinum status. In the second set, all the 10 proteins were specifically increased in PTS group and are therefore interesting candidates for EOC diagnosis or prognostic studies.

Gene ontology analysis. Data analysis of 64 unique proteins identified by two iTRAQ experiments was performed using the Blast2GO database (http://www.blast2go.com/b2ghome) and Web Gene Ontology Annotation Plot (WEGO: http://wego. genomics.org.cn/cgi-bin/wego/index.pl) to class each protein into its respective cellular components, molecular function and biological process (Fig. 2A). For the 64 differential proteins, the subcellular distributions were enriched mainly in extracellular region (90.6 and 78.1\%) (the two numbers represent the upregulated and downregulated proteins proportion of the total, respectively), which imply that most of these proteins are secretary proteins. According to GO molecular function analysis, the top three common functional annotations were binding (87.5 and $93.8 \%$ ), catalytic (28.1 and 56.3\%), and enzyme regulator (25 and 31.3\%). Most of the differential proteins were involved in biological regulation (90.6 and 84.4\%), response to stimulus (81.3 and $87.5 \%$ ), and pigmentation (84.4 and $71.9 \%$ ). To clearly show the expression trend of differential proteins during cancer progress, $\mathrm{k}$-means clustering method was used to classify the 64 protein. The results are shown in Fig. 2E. For further text mining, PANTHER Classification System (http://www. pantherdb.org/) was used to carry out the GO analysis. During tumor progression, 20 proteins were upregulated gradually in cluster A and most of these members participated in immune system process, cell adhesion, and cell communication, which would make sense in connection with drug resistance.

Pathway and biological interaction network analyses. Enrichment analysis of associated diseases and drugs was 
performed for the differentially expressed proteins that met our thresholds (fold, rank) using the IPAD browser (http://bioinfo.hsc.unt.edu/IPAD/) tools. Results of associated diseases and drug analysis showed that 30 proteins (14 upregulated, 16 downregulated) among them were significantly associated with EOC (indicated as pentagrams in Table II) and GPX3 was associated with cisplatin. In addition, DAVID Bioinformatics Resources 6.7 (http://david.abcc.ncifcrf. gov/home.jsp) was used to investigate possible interactions between the 30 proteins associated with EOC, which revealed that the differential proteins were significantly enriched in complement and coagulation cascades and ECM-receptor interaction. To model the signaling network potentially affected in the context of platinum status, the 17 focus proteins with fold changes between PTS and PTR group $>1.5$ were then subjected to network analysis using STRING software (http://string-db.org/). The network analysis identified $A L B$, APOAl,SERPINA1,FN1,ORMI and TF as the major molecules affected in PTR patients (Fig. 2D). Candidate proteins with the most extreme deviation from the NC, BOC, PTS groups, including SERPINA1 (3.8-fold increased), ORM1 (3.32-fold increased), FNI (2.35-fold increased) and cisplatin-associated GPX3 (1.35-fold decreased), were commonly identified in two iTRAQ experiments, and chosen for further analyses.

Co-occurrence analysis with COREMINE. COREMINE was used to performe co-occurrence analysis based on literature. The 64 differentially expressed proteins and the following list of keywords were used to interrogate the tools: drug resistance, neoplasm; drug resistance; drug resistance, multiple. In order to restrict the number of proteins potentially associated with drug resistance or MDR, $p<0.01$ was considered statistically significant. The cumulative frequency top 50 protein lists out of connected proteins, which showed a $p<0.01$ and the 64 differentially expressed proteins were compared to look for the degree of overlap. Finally, proteomic and co-occurrence analysis shared the following 11 proteins: $A L B, C R P, \mathrm{FN} 1, S 100 A 8, T F, V W F, A P O C 2, A P O E, C A T$, $C D 44, F 2$.

Western blotting. A total of 27 serum samples, composing 9 from NC group, 9 from PTS group, and 9 from PTR group, were subjected to western blotting against SERPINA1, ORM1, $G P X 3$ and FN1. These proteins were selected for western blotting primarily the following factors: big fold changes of differential expression, correlation with cancer/drug resistance from a literature-based text mining, the expression trend in four pools and the availability of commercial antibodies. Our results indicated that three of the four candidates have similar trends with the proteomic results (SERPINA1, ORMI, FNI) in the serum of PTR cases, compared to PTS cases, which implied the credibility of proteomic analysis (Fig. 3A-D). One-way ANONA was applied to calculate means \pm SD from each group along with $\mathrm{p}$-values.

Clinical relevance of SERPINA1, ORM1, GPX3 and FN1. In the initial experiment $10 \mathrm{NC}, 10 \mathrm{PTS}$ and 10 PTR samples were used to validate the expression levels of SERPINA1, $O R M 1, G P X 3$ and $F N 1$. The results illustrated that statistical significant difference between PTS and PTR was seen for
SERPINA1, ORMI and FN1, but not GPX3 (data not shown). However, the expression of GPX3, which was observed to be downregulated $(\mathrm{FC}=1.35)$ in proteomic analysis, was not significantly different $(\mathrm{p}>0.05)$ by ELISA. Consequently, we carried a full validation study for SERPINA1, ORM1 and FN1, using the entire 129 samples collected (data are shown in Table I). Consistent with the iTRAQ results in the previous experiment, relative quantitation of SERPINA1, ORM1 and FN1 (Fig. 3F-I) between PTS 52 samples and PTR 44 samples were all found to be significantly upregulated $(\mathrm{p}<0.05)$. Likewise, to further evaluate the diagnostic significance of these three proteins, a ROC curve analysis was constructed for each protein by plotting sensitivity vs. specificity. The overall predictive accuracy of each protein was reflected by the area under the ROC curve (AUC), a commonly used indicator for estimating the diagnostic efficacy of a potential biomarker. FN1 and SERPINA1 with ROC areas of 0.679 and 0.666, respectively, suggest that their use as a biomarker may not be reliable. Unlike the FN1 and SERPINA1, the AUC for ORMI was 0.91 and its sensitivity and specificity for predicting PTR was 71 and $97.4 \%$, respectively, which could clearly separate the PTS patients from the PTR individuals. These results highlight a potential role for ORMI in the response to platinum therapy.

Metabolic analysis. A total of 25,800 metabolic features was observed in our study. Data of identified compounds were subjected to t-test analysis to identify significant metabolic patters and variations. Compounds having $\mathrm{p}<0.01$ and fold-change $>2$ were considered as statistically significant. PCA and multivariate statistics were then applied to identify key PTR-associated metabolic perturbations in PTR compared to PTS. Unsupervised PCA of the resultant data showed clear metabolic separation of PTR from PTS along the first principal component, and clear distinctions of EOC (PTR and PTS) from healthy individuals along the second principal component (Fig. 4A). The BOC sera were not obviously grouped because of their limited sample size. PCA loading plots (Fig. 4B) provided six metabolite features contributing to the separation of groups along PC1 and PC2. Six known compounds were identified using NMR based on database (Table III). The levels of the six potential biomarkers in blood from PTR, PTS and NC group were determined by LC-MS/MS. Compared to PTS, PTR exhibit a specific metabolic trait characterized by decreased levels of calycanthidine and increased levels of 1-monopalmitin, ricinoleic acid methl ester, polyoxyethylene (600)mono-ricinoleate/glycidyl stearate. Furthermore, the concentration of dodemorph was higher and of C16 sphinganine was lower in the EOC compared to NC (Table III). ROC curve was used to calculate sensitivity and specificity of the four biomarkers for PTR compared with PTS. The AUC for 1-monopalmitin, ricinoleic acid methyl ester, polyoxyethylene (600)mono-ricinoleate and calycanthidine was $0.892,0.900,0.883$ and 0.109 , respectively, and their sensitivity and specificity for predicting PTR were 83.8 and $75 \%$; 81.1 and $86.4 \%$; 83.8 and $75 \%$; 90.9 and $73 \%$, respectively, which could clearly separate the PTS patients from the PTR individuals. The combinational four biomarkers achieved an AUC value (AUC=0.925) while the statistical analysis 
Table III. Relevant analytical data for the metabolites identified in PTR, PTS, BOC and NC groups.

\begin{tabular}{lcccccccc}
\hline $\begin{array}{l}\text { Retention } \\
\text { time (min) }\end{array}$ & Adduct & $\mathrm{m} / \mathrm{z}$ & $\begin{array}{c}\text { Error } \\
(\mathrm{mDa})\end{array}$ & $\sigma$ value & $\begin{array}{c}\text { Molecular } \\
\text { formula }\end{array}$ & Trend & $\begin{array}{c}\text { CAS/ } \\
\text { PubChem }\end{array}$ & Possible metabolite \\
\hline 19.9 & {$[\mathrm{M}+\mathrm{H}]$} & 282.2807 & -1.5 & 0.0064 & $C 18 H 35 N O$ & Up (EOC/NC) & $1593-77-7$ & Dodemorph \\
9.4 & {$[\mathrm{M}+\mathrm{H}]$} & 274.2777 & -3.6 & 0.0329 & $C 16 H 35 N O 2$ & Down (EOC/NC) & 4266342 & C16 sphinganine \\
16.9 & {$[\mathrm{M}+\mathrm{H}]$} & 313.2775 & -3.9 & 0.0334 & $C 19 H 36 O 3$ & Up (PTR/PTS) & $141-24-2$ & Ricinoleic acid methyl ester \\
16.8 & {$[\mathrm{M}+\mathrm{H}]$} & 331.2871 & -2.8 & 0.006 & C19H38O3 & Up (PTR/PTS) & $542-44-9$ & $1-$ Monopalmitin \\
19.2 & {$[\mathrm{M}+\mathrm{H}]$} & 341.3071 & -2.1 & 0.0067 & $C 21 H 4003$ & Up (PTR/PTS) & $977137-78-2$ & Polyoxyethylene \\
19.2 & & & & & & & & (600)mono-ricinoleate \\
19.9 & {$[\mathrm{M}+\mathrm{H}]$} & 341.3071 & -2.1 & 0.0067 & $C 21 H 40 O 3$ & Up (PTR/PTS) & $7460-84-6$ & Glycidyl stearate \\
& {$[\mathrm{M}+\mathrm{H}]$} & 361.2419 & -4.6 & 0.0235 & $C 23 H 28 N 4$ & Down (PTR/PTS) & $5516-85-8$ & Calycanthidine \\
\hline
\end{tabular}

PTR, platinum-resistant; PTS, platinum-sensitive; BOC, benign ovarian cyst; NC, normal control; m/z, mass-to-charge ratio; EOC, epithelial ovarian cancer.
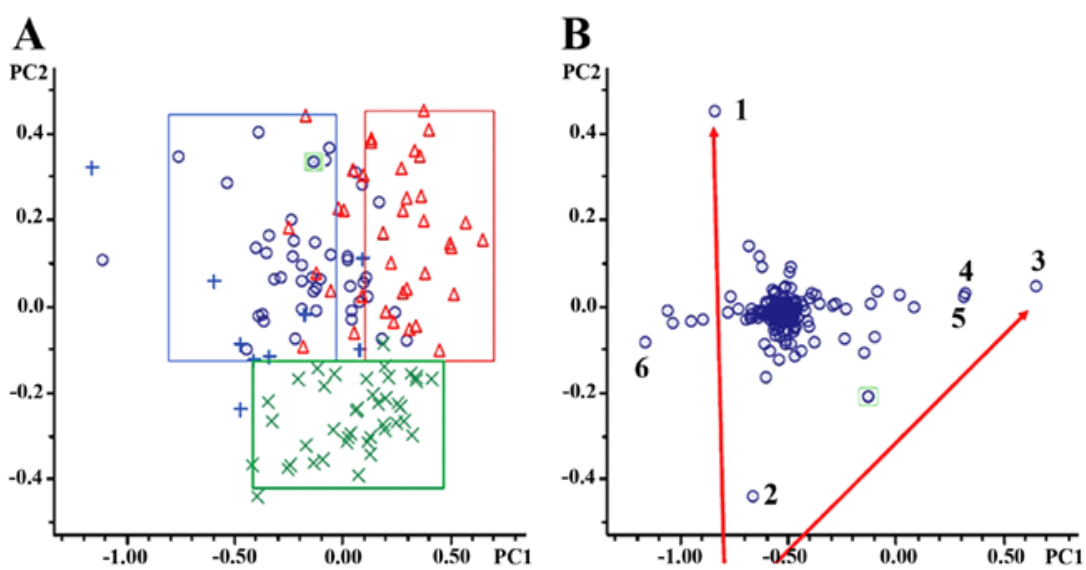

Figure 4. Multivariate statistical analysis. (A) PCA score plots. Blue rings, PTS; red triangles, PTR; blue plus, BOC; green multiplication, NC. (B) PCA loading plots. Selecting compounds far away from the center were assumed to have a greater contribution to the classification of PTS, PTR, BOC, and NC are numbered. PCA, principal component analysis; PTS, platinum-sensitive; PTR, platinum-resistant; BOC, benign ovarian cyst; NC, normal control.

provided $86.5 \%$ sensitivity and $81.8 \%$ specificity for the prediction of PTR (Fig. 5).

\section{Discussion}

Cisplatin is one of chemotherapeutical agents commonly used to treat EOC, which causes DNA damage via forming inter- and/or intrastrand DNA adduct lesions and eventually cytotoxicity. However, the benefits of chemotherapy can be attenuated because of the emergence of platinum resistance. To eradicate the mechanisms of platinum resistance in EOC is a difficult task. The recent development of proteomic approaches applied to investigate drug-resistance mechanisms has greatly helped in addressing these issues. Comparative proteomic approach is a powerful tool, which might help to guide future research and cross validation of various proteomic profiling with a high throughput. In our experiment, a panel of 64 different proteins that have altered expression in PTR patients were compared to the parental PTS group using a shotgun quantitative proteomics approach, and four of these proteins were confirmed with western blotting and ELISA. The results of serum FN1, SERPINA1, GPX3 and $O R M 1$ from 2D-LC-MS/MS analysis were validated in a 139 cohort using a different methodology. Western blotting and ELISA confirmed that the serum level of FN1, SERPINA1 and $O R M 1$ was upregulated in PTR group, which indicated that the FN1, SERPINAI and ORMI serum levels might be a tool for screening and diagnosis of PTR. However, it should be noted that although the change in direction (up- or downregulated) of GPX3 detected by western blotting between PTS and PTR group was consistent with iTRAQ, the changes measured by ELISA assay in 43 patients was not statistically significant $(\mathrm{p}>0.05)$. The differences in fold change determined by iTRAQ, western blotting and ELISA can be attributed to methodological factors such as the use of isobaric tags and/or differences inherent in the technical method. ROC curve analysis was applied to find the cut-off value of serum FN1, SERPINA1 and ORM1 to discriminate between PTS and PTR group. The sensitivity and specificity were calculated. ROC curves show, ORM1 with $71 \%$ sensitivity and $97.4 \%$ specificity could give a higher accuracy (Fig. 3). However, FN1 and SERPINAI were not reliable for clinical diagnosis because of low sensitivity and specificity. Our comprehensive study of proteomics led to the possibility that monitoring the level of 

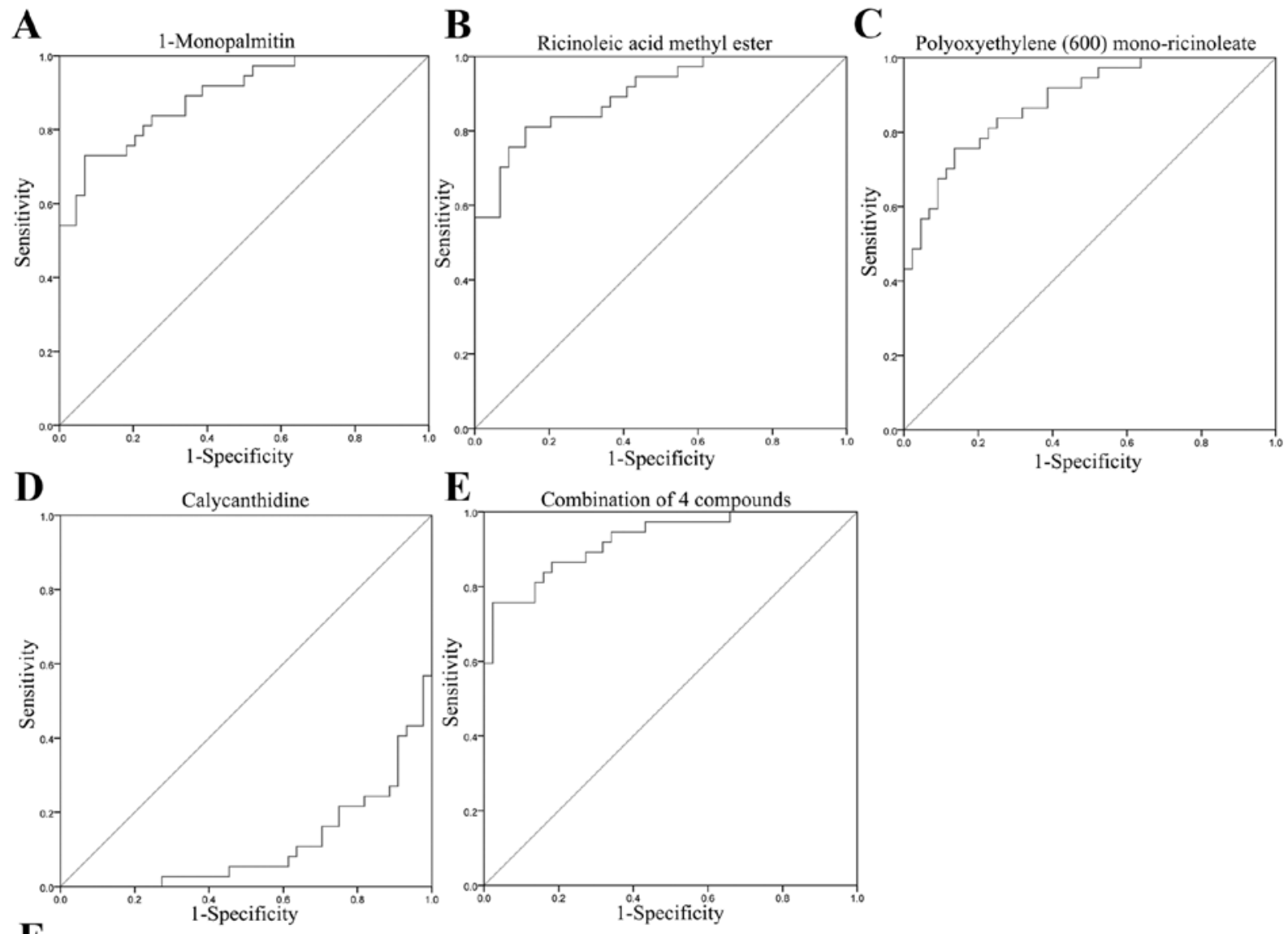

\begin{tabular}{ccccccccc}
$\mathbf{F}$ & \multicolumn{1}{c}{} \\
\cline { 2 - 8 } & Metabolite & AUC & Sensitivity & Specificity & Cut-off & Accuracy & PV & LR $(+)$ \\
\hline $\mathrm{m} / \mathrm{z} 341.31$ & 0.883 & 83.800 & 75.000 & 1221200 & 0.790 & 0.740 & -1.130 \\
$\mathrm{~m} / \mathrm{z} 313.28$ & 0.900 & 81.100 & 86.400 & 1689200 & 0.840 & 0.830 & -0.950 \\
$\mathrm{~m} / \mathrm{z} 331.29$ & 0.892 & 83.800 & 75.000 & 1157500 & 0.790 & 0.740 & -1.130 \\
$\mathrm{~m} / \mathrm{z} 361.24$ & 0.109 & 90.900 & 73.000 & 349094 & 0.830 & 0.870 & -1.260 \\
combination & 0.925 & 86.500 & 81.800 & - & 0.780 & 0.700 & 0.000 \\
\hline
\end{tabular}

$\mathrm{LR}(+)$ : likelihood ratio (+), $\mathrm{PV}_{+}$: positive prediction value.

Figure 5. (A-E) The ROC curves of the candidate biomarkers. (F) Clinical diagnostic performance of the four metabolites in PTR and PTS groups. ROC, receiver operating characteristic; PTR, platinum-resistant; PTS, platinum-sensitive.

serum $O R M 1$ could be clinically useful for the screening and diagnosis of PTR patients.

$\alpha$-1-antitrypsin (SERPINA1) is an inhibitor of serine proteases principally secreted by hepatocytes, but also by monocytes, neutrophils, macrophages and alveolar epithelial cells, and plays a critical role in modulating host immunity, inhibiting T lymphocyte-mediated antitumor function and thereby accelerated tumor proliferation, and metastasis (3-5). Moreover, there have been numerous studies documenting a link between SERPINAl and various cancers, although for most the mechanism for the linkage is unclear. Giving the expression levels of SERPINA1 in rat bladder tumor tissues were 2.5-fold higher than those in normal bladder tissues using two-dimensional difference gel electrophoresis (2D-DIGE) (6). Similar conclusions were also obtained in pancreatic tumors, hepatocellular carcinoma, non-small cell lung cancer, gastric cancer in gastric juice, prostate cancer patients and malignancy in insulinomas. Much attention has been focused on the role of SERPINAI as a tumor suppressor, but no report has shown directly the relation between SERPINAI and chemotherapy drugs. In our study, the contribution of SERPINAI to drug resistance was implicated in human serum samples. SERPINA1 shows one of the largest fold increases (3.8-fold increased) in protein expression level in PTR cohort compared with PTS cohort $(\mathrm{p}<0.05)$. Nevertheless, our data are in good agreement with prior studies elicited above, but disagree with the results of Normandin et al (7).

Fibronectin is a glycoprotein that is involved in cell adhesion, signal transduction and migration processes including embryogenesis, wound healing, blood coagulation, host defense, and metastasis, especially possibly suppression of apoptosis (8-10). There have been many reports on the relation between FN1 and human tumors. Similar thesis reported that fibronectin was involved in Ras, Erk, Akt and ECM pathways and mediate various signals such as cancer cell adhesion, growth migration and invasion $(11,12)$. Akiyama et al showed 
that FN1 played a causal role in tumor neovascularization and metastasis (13). In addition, a recent study found that FN1 is one of the key genes in regulating SOX2 cell migration, invasion, colony formation and drug resistance in ovarian cancer cells (14-16). Qian et al also indicated that FN1 is targeted by let-7g to promote mammary carcinoma cell migration and invasion via p44/42 MAPK and MMPs (17). FN1 was also suggested as a marker for renal cell carcinoma aggressiveness $(18,19)$. Moreover, $F N 1$ was shown to be a direct target gene for miR-1 and miR-200. While miR-1 may play a role as a tumor suppressor gene in laryngeal carcinoma. Similarly, miR-200 is crucial for the maintenance of epithelial identity, behavior, and sensitivity to chemotherapy in ovarian cancer cell line $(20,21)$, which confirmed our previous observation by miRNA microarrays with samples obtained from the same patients as this study (22). All these findings suggest that a functional relation is present between $F N 1$ and platinum response, which supports our data in EOC.

As a member of guutathione peroxidases, GPX3 is located in 5 q23 and has critical roles in the detoxification of hydrogen peroxide and other oxygen-free radicals. Previous studies have demonstrated that GPX3 had a broader downregulated pattern in a variety of cancers, such as ovarian, cervical, thyroid, head and neck, lung, colorectal, gastric, gallbladder, breast, and esophageal cancers than in healthy controls. These reports suggest that GPX3 contains a tumor-suppressor function. The mechanisms involved in mediating the GPX3 tumor-suppressor function are mainly due to promoter hypermethylation (23), the downregulation of c-Met expression $(24,25)$, and the role of antioxidant enzymes which are involved in reactive oxygen species (ROS) metabolism. As a messenger molecule, ROS might increase cancer cell proliferation, genetic mutations, instability, and thereby invasion and angiogenesis (26). In addition, ROS also mediates the induction of tumor cell death via many chemotherapeutic agents such as platinum (27). Although the researchers failed to measure the serum concentration of GPX3, this statement is supported by our results. However, GPX3 is identified to be highly expressed in clear cell adenocarcinoma compared to control tissues at a DNA, mRNA and protein level on cell lines and clinical samples of ovarian clear cell adenocarcinoma $(28,29)$. Although the molecular biological mechanism is not clarified, these results might indicate that $G P X 3$ activity is tumor-specific. In our present study, GPX3 was shown to be downregulated in PTR group compared with PTS group, which confirmed the previous results, but the exact mechanism, in response to anticancer drugs remains to be further understood.

The $\alpha$-1-acid glycoprotein primarily synthesized by the liver is an acute-phase reactant with immunomodulatory and immunosuppressive properties (30) and its serum levels are increased by inflammation, stress, and chronic disease such as cancer (31). Two main biological functions were involved in $\alpha$-1-acid glycoprotein, binding and transporting of endogenous substances or drugs, and a strong immunomodulatory function. Previous investigations in patients with carcinoma of the breast, lung, ovary and endometrium have suggested that serum ORM1 concentrations were increased two times higher than that in healthy individuals, and ORMI might act as blocking agent protecting tumor cells against immunological attack, thereby contributing to the 'immune escape' of the tumor $(32,33)$. ORMI can also interfere with cytokine function by inducing the secretion of soluble $\mathrm{TNF} \alpha$ receptor and IL-1, -6 and -12 receptor antagonist $(30,34)$. Although the mechanisms by which ORM1 mediates its functions are not fully understood, ORMI has been shown to bind to the chemokine receptor $C C R 5$ in macrophages, the asialoglycoprotein receptor in hepatocytes, the surface lectin-like receptor Siglec-5 in neutrophils and can also modulate TNF $\alpha$-induced phosphorylation of p38 MAPK, MEK1/2, c-Jun N-terminal kinase which is required for angiogenesis in macrophages (35-39), but not VEGF-induced signaling. In addition, ORM1 has been shown to enhance endothelial cell migration and capillary tube formation in vitro (40). Moreover, several reports suggested that the serum levels of $\alpha$-1-acid glycoprotein influenced the pharmacokinetics (PK)/pharmacodynamics (PD) of chemotherapy drugs such as docetaxel, PTX and imatinib (41-44). As these reports remarked, $\alpha$-1-acid glycoprotein may function as a carrier of PTX from the serum into the liver via the $\alpha$-1-acid glycoprotein receptors, and this might result in the enhancement of the PTX metabolism. Although ORMI has been reported to be associated with cancers or metabolisms of chemotherapy drugs according to previous reports, no studies have underlined the importance of ORM1 in cisplatin resistance in PTR patients, and this is the first time that $O R M 1$ was identified as an important biomarker of response to cisplatin-based chemotherapy. The mechanism of this phenomenon may be attributed to the PK/PD changes of cisplatin, however, further studies will be required to fully understand $O R M 1$ functional roles in drug resistance.

In the present study, we undertook a non-destructive metabolomic technique (HPLC-micrOTOF-Q II MS/MS) to investigate the metabolic traits. All the six metabolites in our experiment were identified as fatty acid or derivatives. Profiling of metabolomics elucidated changes in the levels of fatty acid metabolism, which confirmed our previous observations by proteome approach and conclusions of many addressed articles on chemotherapeutic resistance and metabolism, and served as an insightful reference to the mechanism research of drug resistance. Fatty acid synthese (FASN) providing proliferating cancer cell lipids for membrane biogenesis was assumed to have metabolic characteristics of cancel cells (45). Expression level of FASN is significantly upregulated in kinds of neoplasm and correlates with poor prognosis, but in a health individual is very low even undetectable, suggesting that FASN serves as a metabolic oncogene (46). Fatty acids were used by proliferating tumor cells for membrane assembly, lipid modifications of proteins, and as an efficient source of energy, all are required to sustain neoplasm growth and survival (47). Furthermore, it is shown that FASN is overexpressed in drug-resistant breast neoplasm cell line (MCF7/AdVp3000), and that reducing the expression of FASN increased the drug sensitivity in MCF7 and MDA-MB-468 (breast cancer cell lines) (48). Analogously, FASN was reported to be associated with acquired trastuzumab/docetaxel/5-fluorouracil resistance in breast cancer or radiation and gemcitabine in pancreatic neoplasm. FASN also played an active role in chemotherapy resistance of HER-2/neu-induced breast neoplasm. FASN not only played a key role in acquired resistant phenotype but also in inherent resistant phenotype in hepatocellular carcinoma (49). Roodhart et al identified two platinum-induced 
polyunsaturated fatty acids which induce resistance to chemotherapeutic drugs. When the central enzymes associated with the production of polyunsaturated fatty acids were blocked, the mesenchymal stem cells induced resistance which was prevented (50). All the above further confirmed the metabolism abnormality of fatty acid is induced by PTR.

In conclusion, we identified a panel of new ovarian epithelial cancer serum protein biomarkers, which have an indicator value for platinum status and allow patients who have a high chance of being resistant to cisplatin-based chemotherapy to receive an alternative therapy. Although thousands of metabolites were identified, links were weak and annotated only a small proportion of the total analytes. In further studies, the role of these differentially proteins or compounds in cisplatin resistance needs to be validated on a large scale to evaluate the clinical benefit of using these candidate biomarkers for diagnosis or prognosis analyses. The contribution of the identified biomarkers in cisplatin resistance should also be explored to help understand and design chemosensitizing agents. In addition, our study demonstrated that metabolomics and proteomics could validate one another partially and their combination could better elucidate the mechanism of drug resistance and provide candidate molecular targets for personalizing therapeutic interventions and treatment efficacy monitoring.

\section{Acknowledgements}

This study was supported by the National Natural Science Foundation of China (grant no. 81572579), Guangxi Scientific Research and Technological Development Program Topics (no. 14124004) and the Specialized Research Fund for the Doctoral Program of Higher Education (nos. 20124503110003 and 2013.01-2016.10).

\section{References}

1. Leonessa F and Clarke R: ATP binding cassette transporters and drug resistance in breast cancer. Endocr Relat Cancer 10: 43-73, 2003.

2. Gottesman MM, Fojo T and Bates SE: Multidrug resistance in cancer: Role of ATP-dependent transporters. Nat Rev Cancer 2 : 48-58, 2002.

3. Zhang D, Wu M, Nelson DE, Pasula R and Martin WJ II: Alpha-1-antitrypsin expression in the lung is increased by airway delivery of gene-transfected macrophages. Gene Ther 10: 2148-2152, 2003.

4. Hansson M, Jönsson S, Persson AM, Calafat J, Tapper H and Olsson I: Targeting proteins to secretory lysosomes of natural killer cells as a principle for immunoregulation. Mol Immunol 40: 363-372, 2003.

5. Cekmen M, Evereklioglu C, Er H, Inalöz HS, Doganay S, Türköz Y and Ozerol IH: Vascular endothelial growth factor levels are increased and associated with disease activity in patients with Behçet's syndrome. Int J Dermatol 42: 870-875, 2003.

6. Lu Y, Liu P, Wen W, Grubbs CJ, Townsend RR, Malone JP, Lubet RA and You M: Cross-species comparison of orthologous gene expression in human bladder cancer and carcinogen-induced rodent models. Am J Transl Res 3: 8-27, 2010.

7. Normandin K, Péant B, Le Page C, de Ladurantaye M, Ouellet V, Tonin PN, Provencher DM and Mes-Masson AM: Protease inhibitor SERPINA1 expression in epithelial ovarian cancer. Clin Exp Metastasis 27: 55-69, 2010.

8. de la Fuente MT, Casanova B, Garcia-Gila M, Silva A and Garcia-Pardo A: Fibronectin interaction with alpha4beta1 integrin prevents apoptosis in B cell chronic lymphocytic leukemia: Correlation with Bcl-2 and Bax. Leukemia 13: 266-274, 1999
9. Schwarzbauer JE and DeSimone DW: Fibronectins, their fibrillogenesis, and in vivo functions. Cold Spring Harb Perspect Biol 3: 3,2011 .

10. Tapper J, Kettunen E, El-Rifai W, Seppälä M, Andersson LC and Knuutila S: Changes in gene expression during progression of ovarian carcinoma. Cancer Genet Cytogenet 128: 1-6, 2001.

11. Mutlu P, Ural AU and Gündüz U: Differential gene expression analysis related to extracellular matrix components in drug-resistant RPMI-8226 cell line. Biomed Pharmacother 66: 228-231, 2012.

12. Ahmed N, Riley C, Rice G and Quinn M: Role of integrin receptors for fibronectin, collagen and laminin in the regulation of ovarian carcinoma functions in response to a matrix microenvironment. Clin Exp Metastasis 22: 391-402, 2005.

13. Akiyama SK, Olden K and Yamada KM: Fibronectin and integrins in invasion and metastasis. Cancer Metastasis Rev 14: 173-189, 1995.

14. Shibata K, Kikkawa F, Nawa A, Suganuma N and Hamaguchi M: Fibronectin secretion from human peritoneal tissue induces $\mathrm{Mr}$ 92,000 type IV collagenase expression and invasion in ovarian cancer cell lines. Cancer Res 57: 5416-5420, 1997.

15. Lou X, Han X, Jin C, Tian W, Yu W, Ding D, Cheng L, Huang B, Jiang $\mathrm{H}$ and Lin B: SOX2 targets fibronectin 1 to promote cell migration and invasion in ovarian cancer: New molecular leads for therapeutic intervention. OMICS 17: 510-518, 2013.

16. Jinawath N, Vasoontara C, Jinawath A, Fang X, Zhao K, Yap KL, Guo T, Lee CS, Wang W, Balgley BM, et al: Oncoproteomic analysis reveals co-upregulation of RELA and STAT5 in carboplatin resistant ovarian carcinoma. PLoS One 5: e11198, 2010.

17. Qian P, Zuo Z, Wu Z, Meng X, Li G, Wu Z, Zhang W, Tan S, Pandey V, Yao Y, et al: Pivotal role of reduced let-7g expression in breast cancer invasion and metastasis. Cancer Res 71: 6463-6474, 2011

18. Waalkes S, Atschekzei F, Kramer MW, Hennenlotter J, Vetter G, Becker JU, Stenzl A, Merseburger AS, Schrader AJ, Kuczyk MA, et al: Fibronectin 1 mRNA expression correlates with advanced disease in renal cancer. BMC Cancer 10: 503, 2010.

19. Yokomizo A, Takakura M, Kanai Y, et al: Use of quantitative shotgun proteomics to identify fibronectin 1 as a potential plasma biomarker for clear cell carcinoma of the kidney. Cancer biomarkers: Section. Dis Markers 10: 175-183, 2011.

20. He X, Wang Y, Zhang W, Li H, Luo R, Zhou Y, Li C, Liao M, Huang H, Lv X, et al: Screening differential expression of serum proteins in AFP-negative HBV-related hepatocellular carcinoma using iTRAQ -MALDI-MS/MS. Neoplasma 61: 17-26, 2014.

21. Cochrane DR, Spoelstra NS, Howe EN, Nordeen SK and Richer JK: MicroRNA-200c mitigates invasiveness and restores sensitivity to microtubule-targeting chemotherapeutic agents. Mol Cancer Ther 8: 1055-1066, 2009.

22. Liu L, Zou J, Wang Q, Yin FQ, Zhang W and Li L: Novel microRNAs expression of patients with chemotherapy drug-resistant and chemotherapy-sensitive epithelial ovarian cancer. Tumour Biol 35: 7713-7717, 2014.

23. Zhang X, Yang JJ, Kim YS, Kim KY, Ahn WS and Yang S: An 8-gene signature, including methylated and down-regulated glutathione peroxidase 3, of gastric cancer. Int J Oncol 36: 405-414, 2010.

24. Bottaro DP, Rubin JS, Faletto DL, Chan AM, Kmiecik TE, Vande Woude GF and Aaronson SA: Identification of the hepatocyte growth factor receptor as the c-met proto-oncogene product. Science 251: 802-804, 1991.

25. Park M, Dean M, Kaul K, Braun MJ, Gonda MA and Vande Woude G: Sequence of MET protooncogene cDNA has features characteristic of the tyrosine kinase family of growth-factor receptors. Proc Natl Acad Sci USA 84: 6379-6383, 1987.

26. Azad MB, Chen Y and Gibson SB: Regulation of autophagy by reactive oxygen species (ROS): Implications for cancer progression and treatment. Antioxid Redox Signal 11: 777-790, 2009.

27. Davis W Jr, Ronai Z and Tew KD: Cellular thiols and reactive oxygen species in drug-induced apoptosis. J Pharmacol Exp Ther 296: 1-6, 2001.

28. Lee HJ, Do JH, Bae S, Yang S, Zhang X, Lee A, Choi YJ, Park DC and Ahn WS: Immunohistochemical evidence for the over-expression of Glutathione peroxidase 3 in clear cell type ovarian adenocarcinoma. Med Oncol 28 (Suppl 1): S522-S527, 2011.

29. Saga Y, Ohwada M, Suzuki M, Konno R, Kigawa J, Ueno S and Mano H: Glutathione peroxidase 3 is a candidate mechanism of anticancer drug resistance of ovarian clear cell adenocarcinoma. Oncol Rep 20: 1299-1303, 2008. 
30. Hochepied T, Berger FG, Baumann H and Libert C: Alpha(1)-acid glycoprotein: An acute phase protein with inflammatory and immunomodulating properties. Cytokine Growth Factor Rev 14: 25-34, 2003

31. Fournier T, Medjoubi-N N and Porquet D: Alpha-1-acid glycoprotein. Biochim Biophys Acta 1482: 157-171, 2000.

32. Fan C, Stendahl U, Stjernberg N and Beckman L: Association between orosomucoid types and cancer. Oncology 52: 498-500, 1995.

33. Duché JC, Urien S, Simon N, Malaurie E, Monnet I and Barré J: Expression of the genetic variants of human alpha-1-acid glycoprotein in cancer. Clin Biochem 33: 197-202, 2000.

34. Tilg H, Vannier E, Vachino G, Dinarello CA and Mier JW: Antiinflammatory properties of hepatic acute phase proteins: Preferential induction of interleukin 1 (IL-1) receptor antagonist over IL-1 beta synthesis by human peripheral blood mononuclear cells. J Exp Med 178: 1629-1636, 1993.

35. Matsumoto K, Nishi K, Kikuchi M, Watanabe H, Nakajou K Komori H, Kadowaki D, Suenaga A, Maruyama T and Otagiri M: Receptor-mediated uptake of human alpha1-acid glycoprotein into liver parenchymal cells in mice. Drug Metab Pharmacokinet 25: 101-107, 2010.

36. Lee YS, Choi JW, Hwang I, Lee JW, Lee JH, Kim AY, Huh JY, Koh YJ, Koh GY, Son HJ, et al: Adipocytokine orosomucoid integrates inflammatory and metabolic signals to preserve energy homeostasis by resolving immoderate inflammation. J Biol Chem 285: 22174-22185, 2010.

37. Gunnarsson P, Levander L, Påhlsson $P$ and Grenegård $M$ : The acute-phase protein alpha 1-acid glycoprotein (AGP) induces rises in cytosolic $\mathrm{Ca}^{2+}$ in neutrophil granulocytes via sialic acid binding immunoglobulin-like lectins (siglecs). FASEB J 21: 4059-4069, 2007.

38. Atemezem A, Mbemba E, Vassy R, Slimani H, Saffar L and Gattegno L: Human alpha1-acid glycoprotein binds to CCR5 expressed on the plasma membrane of human primary macrophages. Biochem J 356: 121-128, 2001.

39. Ligresti G, Aplin AC, Dunn BE, Morishita A and Nicosia RF: The acute phase reactant orosomucoid-1 is a bimodal regulator of angiogenesis with time- and context-dependent inhibitory and stimulatory properties. PLoS One 7: e41387, 2012.

40. Irmak S, Oliveira-Ferrer L, Singer BB, Ergün S and Tilki D: Pro-angiogenic properties of orosomucoid (ORM). Exp Cell Res 315: 3201-3209, 2009.

41. Goh BC, Lee SC, Wang LZ, Fan L, Guo JY, Lamba J, Schuetz E, Lim R, Lim HL, Ong AB, et al: Explaining interindividual variability of docetaxel pharmacokinetics and pharmacodynamics in Asians through phenotyping and genotyping strategies. J Clin Oncol 20: 3683-3690, 2002.
42. Delbaldo C, Chatelut E, Ré M, Deroussent A, Séronie-Vivien S, Jambu A, Berthaud P, Le Cesne A, Blay JY and Vassal G: Pharmacokinetic-pharmacodynamic relationships of imatinib and its main metabolite in patients with advanced gastrointestinal stromal tumors. Clin Cancer Res 12: 6073-6078, 2006.

43. Bruno R, Olivares R, Berille J, Chaikin P, Vivier $N$, Hammershaimb L, Rhodes GR and Rigas JR: Alpha-1-acid glycoprotein as an independent predictor for treatment effects and a prognostic factor of survival in patients with non-small cell lung cancer treated with docetaxel. Clin Cancer Res 9: 1077-1082, 2003

44. Katori N, Sai K, Saito Y, Fukushima-Uesaka H, Kurose K, Yomota C, Kawanishi T, Nishimaki-Mogami T, Naito M, Sawada J, et al: Genetic variations of orosomucoid genes associated with serum alpha-1-acid glycoprotein level and the pharmacokinetics of paclitaxel in Japanese cancer patients. J Pharm Sci 100: 4546-4559, 2011.

45. Pandey PR, Liu W, Xing F, Fukuda K and Watabe K: Anti-cancer drugs targeting fatty acid synthase (FAS). Recent Patents Anticancer Drug Discov 7: 185-197, 2012.

46. Flavin R, Peluso S, Nguyen PL and Loda M: Fatty acid synthase as a potential therapeutic target in cancer. Future Oncol 6: 551-562, 2010.

47. Chen Y, Ma Z, Li A, Li H, Wang B, Zhong J, Min L and Dai L: Metabolomic profiling of human serum in lung cancer patients using liquid chromatography/hybrid quadrupole time-of-flight mass spectrometry and gas chromatography/mass spectrometry. J Cancer Res Clin Oncol 141: 705-718, 2015.

48. Liu H,Liu Y and Zhang JT: A new mechanism of drug resistance in breast cancer cells: Fatty acid synthase overexpression-mediated palmitate overproduction. Mol Cancer Ther 7: 263-270, 2008.

49. Meena AS, Sharma A, Kumari R, Mohammad N, Singh SV and Bhat MK: Inherent and acquired resistance to paclitaxel in hepatocellular carcinoma: Molecular events involved. PLoS One 8: e61524, 2013

50. Roodhart JM, Daenen LG, Stigter EC, Prins HJ, Gerrits J, Houthuijzen JM, Gerritsen MG, Schipper HS, Backer MJ, van Amersfoort M, et al: Mesenchymal stem cells induce resistance to chemotherapy through the release of platinum-induced fatty acids. Cancer Cell 20: 370-383, 2011. 